\title{
SPACE, PLACE, AND PERCIEVED ILLEGALITY: THE UNSANCTIONED PARKDALE OVERDOSE PREVENTION SITE
}

\author{
by \\ Erika Dupuis, BSW, Ryerson University, 2018 \\ An MRP \\ presented to Ryerson University \\ in partial fulfillment of the \\ requirements for the degree of \\ Master of Social Work \\ in the Program of \\ Social Work
}

Toronto, Ontario, Canada, 2019

(C) Erika Dupuis 2019 


\section{AUTHOR'S DECLARATION FOR ELECTRONIC SUBMISSION OF A MRP}

I hereby declare that I am the sole author of this MRP. This is a true copy of the MRP, including any required final revisions.

I authorize Ryerson University to lend this MRP to other institutions or individuals for the purpose of scholarly research

I further authorize Ryerson University to reproduce this MRP by photocopying or by other means, in total or in part, at the request of other institutions or individuals for the purpose of scholarly research.

I understand that my MRP may be made electronically available to the public. 


\author{
ABSTRACT \\ Master of Social Work, 2019 \\ Erika Dupuis \\ Program of Social Work, \\ Ryerson University
}

Space, Place, and Perceived Illegality: The Unsanctioned Parkdale Overdose Prevention Site

In August 2018 the Ontario provincial government ordered the halt of several overdose prevention sites across the province. This paper will focus on an unsanctioned site that opened out of response to resist said closures. This study aims to explore how front-line volunteers navigated opening, maintaining, and closing an unsanctioned overdose prevention site amidst a neoliberal government, and whether it had any impact on service provision. The writer interviewed volunteers who frequently worked at the unsanctioned site, discussing their community, activism, and the ongoing efforts to support people who use drugs. The findings of this research suggest that the perception of illegality had impacts on funding, burnout, and community mobilization.

Keywords: governmentality, harm reduction, people who use drugs, unsanctioned overdose prevention sites 


\section{ACKNOWLEDGEMENTS}

This major research paper would not have been possible without the support of Dr. Purnima George. I would like to extend my sincerest gratitude to Dr. George for her continuous support of my research, for her enthusiasm and direction. Dr. George has taught me more than I could ever give her credit for, and I am indebted to her for her personal and professional guidance.

I would like to thank my mother, whose love and encouragement are with me in whatever I pursue. Lastly, I am grateful to my loving and supportive friends, my chosen family, who provide unending inspiration and motivation. Thank you. 


\section{DEDICATION}

I dedicate this research to the participants of the study, to service providers and organizations committed to reducing social, health, and economic harms related to the war on drugs, and in remembrance of those who are no longer with us. 


\section{TABLE OF CONTENTS}

List of Abbreviations

Page vii

Chapter 1: Introduction

Page \#1

Chapter 2: Literature Review

Page \#6

Chapter 3: Theoretical Framework

Page \#14

Chapter 4: Methodology

Page \#19

Chapter 5: Major Findings and Analysis

Page \#25

Chapter 6: Discussion of Findings

Page \#46

Chapter 7: Conclusion

Page \#52

List of References

Page \#54

Appendix A: Recruitment E-Mail

Page \#60

Appendix B: Recruitment Flyer

Page \#61

Appendix C: Consent Form

Page \#62

Appendix D: Interview Guide

Page \#66 


\section{LIST OF ABBREVIATIONS}

$\begin{array}{ll}\text { CDSA } & \text { Controlled Drugs and Substances Act } \\ \text { CTS } & \text { Consumption and Treatment Service } \\ \text { DCR } & \text { Drug Consumption Room } \\ \text { DTES } & \text { Downtown East Side } \\ \text { NIMBY } & \text { Not in My Backyard } \\ \text { OPS } & \text { Overdose Prevention Site } \\ \text { PWUD } & \text { People/Person Who Use(s) Drugs } \\ \text { SCS } & \text { Supervised Consumption Site } \\ \text { SIF } & \text { Safe/Supervised Injection Facility } \\ \text { SIS } & \text { Safe/Supervised Injection Site } \\ \text { SSR } & \text { Safer Smoking Room } \\ \text { TAVIS } & \text { Toronto Anti-Violence Strategy } \\ \text { TPS } & \text { Toronto Police Service } \\ \text { VANDU } & \text { Vancouver Area Network of Drug Users }\end{array}$




\section{CHAPTER 1. INTRODUCTION}

In 2017, 308 individuals lost their lives due to opioid toxicity in the City of Toronto (City of Toronto, 2019). In the years proceeding, opioid poisoning has climbed into one of the leading causes of death across Canada, contributing to a decrease in life expectancy in some provinces (Gatehouse, 2018; Ye, Sutherland, Henry, Tyndall, \& Kendall, 2018). Activists and community leaders have remained at the forefront of supporting people who use drugs (PWUDs) through harm reduction efforts such as overdose prevention sites (OPSs) (Goldman, 2018).

At its core, OPSs are low-barrier spaces that PWUDs access to receive support and lifesaving interventions. The expansion of OPSs in Toronto is due wholly in part to the tireless work of PWUDs, activists, and frontline workers who strive to bring awareness about the preventable nature of overdose deaths. To support individuals from overdosing OPSs can provide Naloxone, sterile equipment, and a safe environment for people to use. OPSs also consist of communities that advocate for the elimination of stigma, criminalization, unregulated drug supply's, and oppressive and racialized drug policies.

OPSs remain at the epicentre in the fight against drug prohibition; calling on provincial governments and municipal councillors for sustainable action and regulated safe drug supply. Critical interventions such as OPSs can improve access to healthcare for PWUDs but are not enough to solely support individuals who are marginalized by social structures that disadvantage them (Pauly, 2008). Although OPSs have received considerable support from several liberal politicians and policy-makers, there is a NIMBY-ism (meaning Not in my Backyard) that still lingers among local neighbourhoods and select media outlets (Shanoff, n.d.). These stigmatizing discourses continue to shift perception about PWUDs, often viewing drug use as symptomatic of moral failure and disease (Gaetz, 2015). These analyses have gained only further traction with 
the current conservative provincial government calling on a change in direction to support a clinical rehabilitation of PWUDs rather than supporting consumption (The Canadian Press, 2018).

Canadian anti-drug policies have historically and presently perpetuate anti-Black, antiNative, Sinophobic sentiment and structural oppression. These policies, coupled with the prohibition of drugs, are rooted in the racist fear of the immigrant Other, which threatens the moral order of the White settler state (Gordon, 2006). The 1908 Opium Act was the initial Canadian legislature that criminalized the selling and personal use of opium, which was later updated in 1911 to also include morphine and cocaine use (MacKay, 2018). The Act was legislated to target Chinese communities in efforts to cease opium smoking; with its use viewed as a threat to settler states dependence on cheap immigrant labour from the global South (Gordon, 2006; MacKay, 2018). In 1911 the Act was updated to include cocaine; its use at the time was primarily associated with the hyper-sexualization of Black men, threatening the purity of White women and the White, colonial, bourgeois order (Gordon, 2006).

The subsequent war on drugs beginning in the 1960s has not failed but rather, has set out and achieved exactly what it intended to do. The war on drugs has sustained for decades, furthering the oppression and destruction of namely Black, First Nations, Métis, Inuit, and racialized communities across the colonial state. It is a series of profitable policies for and by the state that exacerbate inequitable socio-political and economic conditions. In Ontario, Black men, who over-represent in substance-related charges, are incarcerated at five times the rate of White men and have been intensely targeted and hyper-surveilled through racial profiling in the years following (Khenti, 2014). Similarly, First Nations, Métis, and Inuit communities over-represent in incarceration rates, which comprise of $3.8 \%$ of the colonial state's population but make up 
$21.5 \%$ of people experiencing incarceration (Khenti, 2014). Drug-related racialization that has emerged from the war on drugs continues to reaffirm and associate Blackness and Indigeneity with criminal tendencies, upholding systemic racism and structural violence while also impacting the health and wellbeing of Black and Indigenous communities (Khenti, 2014).

Some describe present-day harm reduction movements as being complicit in the war on drugs for enabling governments to continue causing harm without accepting responsibility for creating said harm in the first place (Miller, 2001 as cited in Roe, 2005). It decentralizes power and social control from the state to the individual by promoting self-management and selfregulation as an interventional practice (Moffatt, 1999 as cited in Roe, 2005). Regulated harm reduction spaces exist because they offer the settler state strong incentives such as cost efficiency, material resources, and public order (Roe, 2005). This critique is not to discount harm reduction as a rational or effective response but rather, that harm reduction movements have succumbed to a mainstreamed, professionalized, risk management strategy.

In August 2018, an unsanctioned OPS opened in Parkdale, Toronto, in response to the provincial government's order to freeze the opening of several OPSs across the province (Giovannetti \& Hauen, 2018). The halt came five days after the Toronto Police Service (TPS) issued a public safety alert noting seven fatal overdoses in Parkdale and its surrounding communities (Bañares, 2018). The tentative closure of multiple OPSs was unprecedented, considering the unwavering support of activists, community members, and healthcare providers who stressed proactive measures needed to support PWUDs.

My interest in exploring this topic is due to my personal and professional endeavours in harm reduction to which I have worked for two years. My education and upbringing has been that of a largely White, Eurocentric, and westernized, cisnormative, pedagogy including ways of 
thinking and knowing. These limitations have significant implications for this research. Research is a subjective account, and as such, I acknowledge that my epistemology will impact how I describe, communicate, and conceptualize participant's voices (Mantzoukas, 2004 as cited in Carter and Little, 2007).

Epistemologies situate political, historical, and economic contexts in research that provide particular academics (namely White bodies) with power and legitimacy to their claims (Gray, 2007). These implications can limit collaborative and change-orientated research processes (Hunter, 2002). The production of this research will contribute to an academic piece that will continue to privilege the global Northern academy and the homogenization of social work knowledge. There are ways in which researchers can disrupt these notions, which include delinking knowledge from imperialist and colonialist ideas (Mathebane and Sekudu, 2018). A critical analysis of existing literature on harm reduction is necessary as numerous works stem from White, cisgender male academics in the global North who mainly use Eurocentric epistemologies and paradigms. As such, I ground this academic work with the epistemologies of those who decentre hegemonic, European epistemologies (Ouijano, 200 as cited in Mathebane \& Sekudu, 2018).

This major research paper will produce a case study of the unsanctioned Parkdale OPS from its inception in August 2018 to its closure in October 2018. It will detail accounts of volunteers navigating limitations amidst a change in government as well as whether there were gaps in service delivery due to its perceived illegality. The purpose of this major research paper is to provide insight into how harm reduction organizers move forward in the political context of a neoliberal, right-wing government. This research also has the opportunity to look at how policy, legislature, and how funding constraints contribute to individualistic harm reduction 
strategies. Through the lens of participants, this study will retell the life of the OPS, how it came to be, and the efforts made to operate the site.

The methodology chosen to study this process is a case study. The theoretical perspective used for this paper will be Michel Foucault's framework of governmentality. The second chapter will explore existing literature around unsanctioned and sanctioned harm reduction spaces. The following section will explain the framework of governmentality. The methodology chapter will describe why the case study method is best suited for this research and will also provide examples of how previous studies have used it. The findings section will then explore the primary research question at hand and will detail the livelihood of the Parkdale OPS site through the volunteers. The analysis section will present these findings within the chosen framework of governmentality. Lastly, the discussion section will cover implications for harm reduction resistance. 


\section{CHAPTER 2. LITERATURE REVIEW}

This chapter will provide an overview of academic literature concerning unsanctioned and sanctioned OPSs as well as governmentality-based scholarship. This chapter will begin by describing a brief history of unsanctioned OPSs in Canada, followed by a literature review. The literature surrounding unsanctioned OPSs in Ontario is particularly scarce. In the omission of these writings, this section has evaluated academic works discussing Safe Injection Sites (SISs),

Safer Smoking Rooms (SSRs), and Supervised Consumption Sites (SCSs). The articles presented can be categorized into three distinct themes: unsanctioned sites and perceptions of illegality, attempts in operating barrier-free services, as well as neoliberal critiques of harm reduction practices and spaces.

\section{A Brief History of Unsanctioned Overdose Prevention Sites in Canada}

In Canada, unsanctioned OPSs began to pop-up in Vancouver's Downtown East Side (DTES) in 2016 (Wallace, Pagan, \& Pauly, 2019). The first pop-ups opened in response due to the absence of options in accessing the then present, sanctioned, SCSs (Wallace et al., 2019). Initially, the pop-up OPSs were to be a tentative, a mobilizing effort to save lives due to the lack of response by the provincial government (Wallace et al., 2019). In an unprecedented move, and after several sites continued to pop-up in the DTES, the provincial government mandated a public health emergency that saw accelerated sanctioning of various OPSs across Vancouver and the province (Wallace et al., 2019). The mandate was a Ministerial Order that allowed for the province and the OPSs to bypass the Controlled Drugs and Substances Act (CDSA), allowing for formal sanctioning (Wallace et al., 2019). Following this order, all regional health authorities across the province were directed to set up and fund overdose prevention services (Wallace et al., 
2019). Within the year, it was recorded that 550,000 visits had occurred to various OPSs across the province, which included 2500 non-fatal overdoses (Wallace et al., 2019).

Ontario's first unsanctioned OPS opened in August 2017 due to similar constraints and the lack of SCSs and SISs (Glauser, 2018). The unsanctioned OPS, which opened in Moss Park, initially received an undeclared provision from the City of Toronto and the TPS (Glauser, 2018). In December 2017, the federal government announced it would let the provincial government sanction and fund OPSs without the sites having to apply to Health Canada for exemption from the CDSA (Glauser, 2018). In the years following, several unsanctioned sites have opened across Ontario; only a handful of which have opened in the greater Toronto area. The following section will now hone in on three distinct themes found within the literature reviewed. These themes include unsanctioned consumption spaces, barriers in accessing services, as well as neoliberalism and harm reduction.

\section{Unsanctioned Sites and Perceptions of Illegality}

Although it is not a physical space, Smith (2012) discusses perceived illegality and anarchism in the origins of harm reduction. Its roots were an illegal practice in which front line workers risked arrest - an intentional act of civil disobedience - for supplying sterile sharps to PWUDs (Smith, 2012). Its original intention was not the elimination of drug use, but to recognize that use is inevitable, and as such, it should look to reduce individual and social harms (Smith, 2012). Smith (2012) goes on to collate anarchism and harm reduction through its mutual principles of anti-authoritarianism, mutual aid, and distrust of hierarchy. The author describes harm reduction as a disguised language developed to form a model of care for capitalism's most oppressed. I equate these values to be reflective within the work of the following unsanctioned sites. 
Davidson, Lopez, \& Kral (2018) explore the theme of perceived illegality through their article on an unsanctioned supervised injection facility (SIF) in the United States. Advantages of being an unsanctioned SIF included a "for us, by us" approach. Said approach comprised of community members being engaged in every aspect of creating and operating the site, including the creation of guidelines and mobilizing rapidly in response to overdose (Davidson et al., 2018). In contrast, the authors found limitations in the site's operation as it focused predominately on concealing itself and keeping out of the public eye. Similarly, participants expressed that there were setbacks in discussing the site with local agencies, resulting in a lack of referrals to broader health and social service organizations. Comparably, the Kerr, Oleson, \& Wood (2004) article indicated that unsanctioned SISs are a crucial public health function that increases the reach and effectiveness of harm reduction interventions. These methods of activism, however, can have dire consequences for volunteer and peer workers, including burnout and arrest.

Unsanctioned SSRs exhibited similar research findings in comparison to unsanctioned SIFs. In McNeil, Kerr, Lampkin, \& Small (2015), authors explored how SSRs shape crackrelated harms through ethnographic research. The results recognized how an unsanctioned SSR pop-up within a SIF was a practical solution where participants could smoke free of social, gendered, and structural violence (McNeil et al., 2015). While the creation of an unsanctioned SSR proved to be a positive addition to the establishment, the authors described increasing difficulties in balancing demand and access due to the limited operational capacity. McNeil, Small, Lampkin, Shannon, \& Kerr (2014) conducted ethnographic research, conceptualizing assisted injection practices in an unsanctioned Supervised Drug Consumption Room (DCR). Their findings revealed the impacts of assisted-injection prohibitions, which create structural 
barriers for service users that leave them vulnerable to violence and blood-borne related infectious diseases (McNeil et al., 2014).

In response to the lack of support for PWUDs in accessing syringes, the Vancouver Area Network of Drug Users (VANDU) began operations on an unsanctioned, peer-led, syringe exchange program (Wood et al., 2003). The syringe exchange was shown to be vital for PWUDs in Vancouver's Downtown East Side as it provided sterile sharps, assisted injecting practices, and safer disposal methods (Wood et al., 2003). Wood et al. (2003) notably highlighted the detrimental harm that would come from the shutdown of the site if law enforcement were to intervene.

\section{Operating Barrier-Free Services}

Several works also explore a central theme regarding strategies in creating barrier-free harm reduction spaces as well as barriers to accessing said spaces. Shaw et al., (2015) investigate the feasibility of SISs in Ottawa using a quantitative cohort and community-based participatory research approach. In their work, Shaw et al., (2015) were able to identify community needs imperative to the potential creation of an SIS, including assisted injections, community consultations with local police, as well as community ownership and control. Comparably, Mitra et al., (2017) conducted a quantitative survey in London, Ontario to gauge participants view on design preferences and essential amenities for a potential SIS. Similar to the works of Shaw et al., (2015), Mitra et al., (2017) found that SISs in this geographical area has the potential to connect vulnerable communities to medical care, clean equipment, emergency response, as well as referrals. Further findings included operational designs such as women's specific drop-in times, as well as women-centred health and social service programming. 
Wallace, Pagan, and Pauly (2019) conducted a case study on three OPSs in Victoria, British Columbia to highlight the implementation and impact of services in each OPS. Barriers to implementation included the need to open sites quickly but being limited in terms of being viewed as only a temporary, emergency service (Wallace et al., 2019). Further barriers included the continued criminalization and stigmatization of PWUDs, being physically placed where abstinence was highly encouraged, and adopting federal health and safety procedures that did not reflect the needs of the community (Wallace et al., 2019).

Small et al.'s (2011) research on established SISs in Vancouver explore how conventional policies and procedures can be improved building off the perspectives of participants and their experiences concerning barriers in accessing the site. Difficulties faced by participants were mainly in part to neoliberal monitoring and regulating practices (Small et al., 2011). These difficulties include signing waivers, prohibiting assisted injections, banning the selling or passing substances of within the facility, issues in wait times and time limits, as well as suspensions and removal of participants (Small et al., 2011).

Issues in operating barrier-free services may also stem from outsider communities. Davidson and Howe (2014) discuss their efforts in relocating their consumption space a mere 150 metres from its original location and the backlash that followed. The adverse reactions and NIMBY-ism, according to Davidson and Howe (2014), were due in part to the defensiveness of upper-middle-class residents and their space. The authors note that this resulted in producing tightly-constrained categorizations of desirable and undesirable activities of PWUDs in the area. Similarly, Smith (2010) explores NIMBY-ism in the Toronto context for a methadone clinic. Smith (2010) affirms the politics of space by detailing experiences of socio-spatial exclusion and stigmatization tactics. These tactics situate PWUDs as a threat to the purity of the city's safety 
and economic productivity (Smith, 2010). NIMBYs misperception of risk can be attributed to negative, misinformation on the part of the government and the lack of evidence on the community benefit for SCSs (Kolla et al., 2017).

While there may be pressure by NIMBYs and outsider communities to relocate harm reduction organizations or agencies, what occurs when they are successful in the shutdown of said service? MacNeil and Pauly (2010) capture this through their case study on the closing of Canada's largest and oldest operating needle exchange. As a result of community pressures, the organization re-established their work in the form of a mobile exchange service (MacNeil \& Pauly, 2010). Although their services still existed, the new change in service delivery led to a decline in participants, as well as multiple reports stating that participants were reusing and reselling sharps (MacNeil \& Pauly, 2010).

\section{Neoliberal Critiques of Harm Reduction Services}

The aforementioned academic articles speak to themes and experiences of perceived illegality as well as examples of community-informed, barrier-free harm reduction services. The later articles described will now hone in on my chosen theoretical perspective, governmentality within harm reduction services. Elliot (2014) conducted ethnographic research on a sanctioned SIS in Vancouver, uncovering the neoliberal tactics that led to the sanctioning of the site and the biomedical discourses it has created as a result. Although this particular SIS was born as a result of harm reduction activism, Elliot (2014) argues that liberal scientists and neoliberal actors reinforce the power imbalances they seek to eliminate including managing and surveillance of participants.

Comparably, Moore (2009) conducts an ethnographic study on how health service providers ignore power relations between themselves and clients, ultimately reproducing 
neoliberal discourses surrounding autonomy, rationality, and responsibility. Moore (2009) notes in their findings that PWUDs often are required to adopt a subject position as 'chaotic' or 'failed' to receive any social model of health care. While Solai, Dubois-Arber, Benninghoff, \& Benaroyo (2006) do not use governmentality as their theoretical framework, their phenomenological research explores critical ethical issues within a DCR that contribute to overarching neoliberalist policies. In their work, Solai et al., (2006) reveal that service providers within a Swiss DCR routinely experienced professional and institutional service barriers due to restrictive policies, this includes a prohibition of assisted injections, as well as denying access to minors and pregnant clients.

Fischer, Turnbull, Polland, and Haydon (2004) conceptualize SISs using a post-welfarist governmentality lens in their research. In deconstructing SISs, the authors recognize how the state utilizes consumption spaces as a means to gain control of PWUDs by manifesting a responsible, self-managing citizen. (Fischer et al., 2004). They further this analysis by theorizing SISs as a process to create social and urban order - to reduce deviance and nuisance and reemphasize public order. Wolfson-Stofko et al., (2016) use a similar lens of neoliberalism, but use the said theory in practice by deconstructing SIFs in their research study. Wolfson-Stofko et al., (2016) detailed the 'audit culture' within harm reduction spaces that emphasize minute details to ensure taxpayer money is not gone to waste.

To be critical of harm reduction interventions, such as SIFs or OPSs, is to be critical of social policy that governs such spaces as well. Bunton (2001), describes how amendments made to health and social policy in Western states have emphasized enterprise, self-reliance and regulation, and the deregulation and restructuring of organizations. Bunton (2001) also emphasizes that in the colonial state, scientific knowledge and discourses - rather than everyday 
experience - will always remain as the basis for constructing and disciplining the intoxicated body. This coloniality of power is prevalent within the emergence of prevention science, which establishes normative goals, control, regulation, and dismissal that reality is open to contestation (Roumeliotis, 2015).

This chapter has analyzed numerous academic pieces that provide relevant material moving forward in this study. The research articles explored showcase a need for further studies on unsanctioned harm reduction spaces. These studies also highlight the necessity of researchers to interrogate the responsibilization and self-management of PWUDs and service providers. The following chapter will explore, based on this literature review, the theoretical framework and its relevance for this research. 


\section{CHAPTER 3. THEORETICAL FRAMEWORK}

This chapter will describe the theoretical framework chosen, provide a rationale for its use, explore its use in harm reduction research, its use for this particular research topic, and detail how governmentality is applicable for a case study methodology.

Governmentality is a framework that identifies the deliberate and interwoven strategies used in societies to cast who is knowable and governable (Foucault, 1991, as cited in Villadsen, 2008). It is an attempt by governments to shape and create 'rational' behaviour and thought with rationality being what is considered to be social 'norms' (Hardy, 2013). Governmentality also refers to a process in which governmental forces, including institutions and dominant discourses, conduct populations under a gaze of authority, transferring state power to the individual level to hold individuals accountable for their actions (Rose et al., 2006, as cited in Iacobucci \& Frieh, 2018). A key tenet of governmentality is the theory of responsibilization, which includes transfers of power from the state to the individual. Responsibilized subjects assume specific responsibilities of the state concerning social conditions such as health, finances, and housing (Hoffman Birk, 2017). This intentional act conflates autonomy and independence with self-responsibilization, in that, individuals reproduce social norms, assemblages, and community (Clarke, 2005 as cited in Hoffman Birk, 2017). The power of responsibilization and the creation of responsible citizens will be in discussion throughout this study and its findings.

Foucault describes governmentality as a process that subjectifies individuals rather than objectifying them (Foucault, 1982 as cited in Garland, 1997). Willing individuals take on this subjectification in conformity to specific governmental aims (Foucault, 1982 as cited in Garland, 1997). Aside from the individual account, Rose and Miller (1992) describe how the state problematizes certain groups and ways of life if they do not align with the political objectives of 
the state. The construction and control of crime, for instance, transforms into measurable objectives by the state, which includes the emergence of cost-effective, economically efficient, harm reduction-based measures (Garland, 1997).

Governmentality is an appropriate choice in researching perceptions of illegality and the impacts it may have on individuals and communities. In utilizing Hiemstra's (2010) work on governmentality, I situate illegality as a racialized and spatialized social condition that marginalizes and criminalizes PWUDs. Illegality occurs out of careful manipulation of the law, resulting in discourses of exclusion and domination (Hiemstra, 2010). The governmentalitybased discourses that emerge from perceived illegalities reiterate that certain communities can and should be targets of governance.

Social workers, in particular, are implicated within governmentality as they have the potential to be powerful actors of the state, supporting the self-responsibilization of subjects and within this context, PWUDs. In exploring this implication, I draw upon Wilson's (2008) article on governmentality discourses and practices within the social work realm. Wilson (2008) explores how within social work, practitioners engage in governance through conceptualizations of vulnerability and community. The discourses surrounding community work with "vulnerable" and "deserving" populations pave the way for normalizing of exclusion through responsibilizing individuals for their social and economic issues (Wilson, 2008). The author situates practitioners as the altruistic giver, while the individual is as the user and receiver. Similarly, the author also describes new, political contextualizations of community which are primarily associated with solution-focused, risk management work. These contextualizations are present in the shift of community-run to community-led initiatives and organizations (Wilson, 2008). Community, in 
this sense, is regarded as a means to locate a certain "problem," ignoring structural and systemic factors that contribute to it (Wilson, 2008).

In using governmentality as the theoretical framework for this research, I will be able to frame how volunteers at the unsanctioned Parkdale OPS site provided service to PWUDs. Sanctioned OPSs, along with SISs and SCSs, are bound to and governed by a set of strict policies and procedures put forth by the provincial Ministry of Health and Long-Term Care. Thus, this piece of research is unique in the sense that it will capture how volunteers continued to use the same structure of a government-sanctioned OPS, but how it was ultimately considered illegal due to the sudden halt on the opening of various OPSs across the province. Its illegality may have allowed volunteers to shift or change how they perform due to the lack of governmental oversight or a need to abide by mandated policies and procedures. Still, volunteers are active within a governmentality process of translating state power to the individual, promoting regulating, self-policing tactics in PWUDs behaviour (Iacobucci \& Frieh, 2018). It is possible that the experiences of operating an unsanctioned OPS will be similar to that of a paradox of being community-driven, yet government-directed in which volunteers actively object authoritative state power and what it stands for but are also complicit in maintaining said power and control. Unsanctioned sites open as an act of civil disobedience, yet also provide concealed space for PWUDs to engage in civil disobedience (Wallace et al., 2019).

In terms of harm reduction spaces, such as OPSs, governmentality has been used to describe how substance use has shifted away from punitive measures into a means of regulating and controlling the PWUDs use (Fischer et al., 2004). Some individuals describe people who seek out services such as OPSs as being socially controlled, this control, however, and who is anticipated to partake in it, differs by race and class (Netherland, 2011 as cited in Iacobucci \& 
Freih, 2018). In some ways, these sites support an individual's 'choice' to substance use while giving them tools that teach skills and information needed to avoid deviant or criminal behaviour (Iacobucci \& Freih, 2018). OPSs, like SISs and SCSs, are often encouraged by health providers as an 'option' for PWUDs to 'take control' in their lives - this, however, leads to the conformity of social norms in assembling the productive, accountable, and responsible behaviours of the PWUD (Iacobucci \& Freih, 2018).

Governmentality is frequent in harm reduction research. Its use describes how harm reduction becomes reflective of counter-politics, where politically leftist individuals and organizations co-opt science and evidence-based models to advocate for the implementation of SISs (Elliot, 2014). Non-profit, grassroots, and community-based agencies undertake these neoliberal projects, such as a SISs, so that governments can generate profit from a particular need and response to underprivileged communities (Adams, 2013 as cited in Elliot, 2014). Researchers suggest through cost-benefit analyses that SISs have been shown to produce a high economic benefit to the state through the decrease of 'chaos' and 'public disorder' of PWUDs (Andresen \& Boyd, 2010 as cited in Elliot, 2014). Governmentality is also relevant in critiquing service delivery models. Villadsen (2008) asks, how is service delivery used to produce knowledge about participants? How do we then turn them into objects of the government? What kind of subject is then required to fulfil this role? This critical thought, along with the abovementioned questions, will serve as a foundation for this governmentality-based scholarship.

This chapter has described in detail the reason for employing governmentality as a theoretical framework for this study. It conceptualized the theory, justified its application in this study, and provided further rationale by comparison to other harm reduction studies. The 
following section will build off of this chapter in describing the reason for a case study methodology approach. 


\section{CHAPTER 4. METHODOLOGY}

This chapter will unpack what constitutes a case study methodology, describe its historical implications as well as defining its unique characteristics. This chapter will also explore its use in similar research studies regarding substance use and harm reduction. Finally, this chapter will end in justifying the use of a case study in this particular study, including the specific methods used to collect data and data analysis.

In utilizing a case study methodology, researchers study real-life events within a contemporary setting (Yin, 2009 as cited in Creswell, 2013). Some suggest that case studies represent both an object of study as well as a product of inquiry (Creswell, 2013). Researchers can choose to complete one of two types of case study: bounded systems and multiple bounded systems (Creswell, 2013). The author describes the first being a single case, while the latter represents multiple cases over time. Both styles of case study require detailed, in-depth data collection. These methodologies, however, include multiple sources of information such as observations, interviews, documents, and reports, all of which resulting in themes and descriptions of the case itself (Creswell, 2013). Lastly, Creswell (2013) also describes how case studies may vary in its unit of analysis which can comprise either a multisite study (multiple cases) or a single case study (a within-site study).

Currently, case studies are utilized in law, medicine, psychology, and political science fields but have historical connections to anthropology and sociology work (Creswell, 2013). Notable works using case study methodology include LePlay's study of families as well as the University of Chicago's Department of Sociology in their studies on Polish communities in Europe and America (Creswell, 2013). The use of case study methodologies has grown in 
varying disciplines but has also contributed to a broadening development of case study styles including explanatory, exploratory, and descriptive methods.

There are distinct features of a case study that separate it from other methodologies in qualitative research. First, case studies begin by defining a particular case to be studied, which can include individuals, communities, relationships, small groups, specific projects, or an organization (Yin, 2009). Regardless of what the researcher may choose, it is critical that the case to be studied is bounded by place or time (Yin, 2009). Equally important is the intent of conducting a case study which can either be an intrinsic case study or an instrumental case study (Stake, 1995). Intrinsic case studies look at stand-alone cases that are described and detailed methodically while instrumental case studies look at a broader issue and choose a specific case to study the problem (Stake, 1995). In terms of analysis, case studies can use either a single case, multiple units within a case, or the entire case (Creswell, 2013). Themes identified within a case study methodology are chronologically organized and often end with a conclusion that expresses the overall meaning of the case (Creswell, 2013).

Although research on unsanctioned overdose prevention sites is limited, research surrounding this topic has often utilized a case study methodology. Small, Palepu, and Tyndall (2006) used an intrinsic, single case study methodology to showcase how attitudes on SIFs shifted throughout time, leading up to the opening of Canada's first legal SIF. Kerr et al., (2006) also utilize an intrinsic, single case study methodology to provide a rich, in-depth history surrounding a peer-led SIS. Similar to the research topic at hand, MacNeil \& Pauly (2010) used an intrinsic, single case study methodology to capture the impact of closing Canada's largest needle exchange. 
Researchers utilize case study methodologies when they are unable to separate the setting and context with the phenomena at hand (MacNeil \& Pauly, 2010). This research conducted a single, within-site, intrinsic case study. It focused on capturing the unique experiences and challenges in service delivery of volunteers at the unsanctioned Parkdale OPS and more specifically, whether its perceived illegality added any additional barriers to service provision.

In the earlier analyzed studies, the researcher and research team have been the primary producer of knowledge. Articles such as Mitra et al., (2017), Shaw et al., (2015), Elliot (2014), and Solai et al., (2006) use either very little or no direct quotes from participants, engaging in the exclusion of personal narratives by substituting their own subjective account of the research experience. Other means of exclusion, which is relevant in all literature reviewed, is the voices of individuals who do not have the means to access consumption sites. Additionally, and in all literature, there is no perspective of individuals who willingly choose to not participate in these sites. Researchers should anticipate this act of exclusion; however, it is essential for researchers to acknowledge how these sites may perpetuate further marginalization of PWUDs. In response to the mentioned critiques, I drew upon Heron's (2005) work, using a critical self-reflexive process to conceptualize the power of both my subjectivity and research. Critical self-reflexivity does not stop in the early stages of research development but should be observed throughout the research process in detail, such as methodology, data collection, data analysis, and dissemination.

To establish an in-depth understanding of the case, this research study comprised of a chronology of events at the unsanctioned Parkdale OPS from its inception to its closure from the view of volunteers. The case or main unit of analysis was the unsanctioned OPS itself. Case study methodologies often employ multiple sources of data; however, due to certain limitations, 
this research focused only on primary data through interviews of volunteers and participants. No direct, participant observation was utilized as a data point because the site was not active. The data collected has been used to provide a holistic analysis of the entire case, focusing on a few centralized themes to understand the complexity of such a case (Yin, 2009).

This research interviewed two volunteers who provided service at the unsanctioned Parkdale OPS. Purposive sampling techniques were used to interview volunteers who frequented the site. Within this context, frequent constitutes as volunteering at the site as little as one to two times per month and as consistent as every week. Initially, this study was to recruit both service providers and service users as viewed in the appendices; however, due to time constraints, only service providers were interviewed. Recruitment of volunteers and was established through emails to harm reduction collectives in Toronto as well as several neighbouring community health centres that operate harm reduction programs (see Appendix A). Each email requested that my study information be passed along to their listserv and, or, staff directory along with a visual flyer (see Appendix B). For interviews, volunteers were asked to locate an accessible space for them to engage in conversation for an hour and to sign a consent form agreeing to participate in the study (see Appendix C). Interviews were semi-structured, allowing for both in-depth, specific questions as well as naturally arising, spontaneous inquiries (see Appendix D).

The case study methodology holds a specific method of data analysis. This study applied a holistic analysis, looking at the entirety of the case rather than a specific aspect of it (Creswell, 2013). In using this approach, a detailed picture of the case was developed, which included a history of the case, a chronology of events, as well as day-by-day accounts (Creswell, 2013). Following this, a thematic analysis was deployed to understand the complexity of this case by identifying recurring and common themes throughout the research participants (Creswell, 2013). 
Considering that case studies are often utilized to gain an understanding of an exceptional circumstance, this analysis ended through an interpretation of the meaning of the case and lessons learned.

Researchers must consider particular ethical considerations and limitations within any study. First, and as previously noted, this study is limited in its data collection as the unsanctioned OPS is no longer operating, which limits participant observation. It is also limited in document and policy analysis as no data was available or gathered for either source. I utilized several strategies to address ethical considerations within this research study.

As previously mentioned, this research contributes to ongoing social work knowledge that privileges global, Northern, academies. A critically reflexive shift within the research process is fundamental to addressing and dismantling further imperialist knowledge production (Hunter, 2002). There are several ways in which I have addressed these limitations, namely drawing on insight and suggestions from various critical scholars within harm reduction research. The first is the understanding that knowledge is not neutral or objective and that there are multiple truths and realities (Foucault, 1984). The second understanding is that researchers must be reflexive when participants are constructing and retelling their truths (Hunter, 2002). Participants knowledge may not be viewed as equal in status, which can empower or disempower the individual (Hunter, 2002).

In being actively reflexive, I have addressed limitations by way of methods. In using a governmentality framework, I actively engaged with participants not just in the data collection process, but built a participant-researcher relationship through the analysis and writing of the MRP. Participant collaboration includes them representing participants voice in not only the writing but also in developing the paper. Drawing upon the work of Rubin \& Babbie (2013), a 
critical epistemology, similar to one I have personally developed, is one that views knowledge and phenomena as existing in multiple, hidden layers. This approach often looks at the researcher as a critical expert that mobilizes participants to take on the research findings (Rubin \& Babbie, 2013). While I may be an expert in my personal experience with addiction, my methods and methodology considered participants as experts, not myself. In uncovering the rich experiences and phenomena of operating an unsanctioned overdose prevention site, I have brought forward participants' choice whether they wish to further advocate for overdose prevention sites using this research. Through the abovementioned methods, I have contested hegemonic ways of knowing and producing research.

This chapter has described the research method, case study, as well as a rationale for its use. It has also provided an overview of sources of data, recruitment and sampling techniques, data collection methods, as well as the case study method for data analysis. This chapter has concluded with specific limitations and ethical considerations for this study, including approaches to address said considerations. The following chapter will outline the major findings of the study as well as a case study method of analysis. 


\section{CHAPTER 5. MAJOR FINDINGS AND ANALYSIS}

In utilizing a case study methodology, this chapter will begin by providing a profile of the participants and a brief geography of Parkdale. The following section will include a chronology of events, as well as daily accounts of the site as described by participants. Subsequent findings will include an analysis of statements recounted by participants who provided service at the unsanctioned OPS.

\section{A Profile of Participants}

In total, two participants were recruited for this study. This study will not provide descriptive features of participants in order to maintain confidentiality as their disclosures may risk their employment in the field. Volunteers will hereafter be described as participants of the research study. Participants were asked one of two questions: first, how would they describe their role at the site and second, how often they provided service at the site. Participant 1 described themselves as a harm reduction worker who frequently volunteered at the unsanctioned OPS, upwards of two times per week. Participant 2 described themselves as a peer worker who volunteered at the site on a biweekly basis.

\section{A Geography of Power and Spatiality in Parkdale, Toronto}

In situating this research geographically, it is necessary to interrogate the dominant conceptualizations of Canadian, and namely Toronto, geography which include the ways in which the settler, colonial state is active in the displacement of Black, Indigenous, and racialized communities from certain spaces (Edmonds \& Banivanua-Mar, 2010 as cited in Hunt \& Stevenson, 2017). In describing Parkdale, I lay out a geographic context complicated by the dispossession of stolen Indigenous lands (Hunt \& Stevenson, 2017). To recognize Parkdale is to ultimately recognize that its bounded geography represents contested territory and 
institutionalized power (Hunt \& Stevenson, 2017). As such, I situate this research within this view.

In the 1870s, Parkdale was designated as a rapidly up-and-coming neighbourhood; a quaint suburb just West of Toronto with five railway lines leading to the Downtown core (Whitzman \& Slater, 2006). At the time, the makeup of Parkdale primarily consisted of families, skilled labourers, and self-employed small business owners (Whitzman \& Slater, 2006). In this time frame, Parkdale was also within proximity to the Toronto Central Prison, the Andrew Mercer Reformatory for Women, the Home of the Incurable, the Protestant's Orphan Home, as well as the Ontario Lunatic Asylum (Teelucksingh, 2002; Whitzman \& Slater, 2006).

It was in the early 1900s, where the division between North and South Parkdale, separated by Queen Street, originated (Teelucksingh, 2002). Semi-detached homes were being rapidly built in North Parkdale by White, affluent, settlers while apartments and flats were predominately occupied in the South by lower-income, Black, Indigenous, racialized, and newcomer communities (Whitzman \& Slater, 2006). The distinction between North and South Parkdale led to a certain moral panic and subjectification of South Parkdale residents who lived in multi-unit homes often referred to as 'disease-breeding tenements,' 'breeders of slums,' and 'chicken coops' (Whitzman \& Slater, 2006). By the mid-1920s Parkdale was designated as the central meeting spot for the Klu Klux Klan of Canada who made public outcries about multi-unit housing and the 'invasion of foreigners' which threatened the White Settler order and the nuclear family (Whitzman \& Slater, 2006). The construction, however, of multiple unit homes, continued to rise over the years following World War I and World War II (Whitzman \& Slater, 2006). 
In the years following, several single-family homes developed into multi-unit dwellings and rooming houses (Horgan, 2018). In the 1970s City of Toronto established several social housing projects in South Parkdale, many of which dedicated to group homes and outpatient psychiatric care following psychiatric deinstitutionalization (Teelucksingh, 2002). Parkdale in this time had become synonymous with stigmas and discourses correlating mental illness to poverty and single-room occupancy (Horgan, 2018). Since the 1990s and onward, Parkdale has continued to experience commercial and residential gentrification, pushing out mainly Black, Indigenous, racialized and newcomer communities in place of galleries, cafes, young professionals, and wealthy families (Horgan, 2018). The conversion of flipping rooming houses into single-family homes, elimination of rent control by previous governments, as well as neoliberal strategies to shame and punish the poor have contributed to the ongoing stigmatization, gentrification, and displacement of Black, Indigenous, and racialized communities of Parkdale (Horgan, 2018). In response, several community organizers and organizations have created new spaces of resistance in areas of housing, harm reduction, and environmental injustices (Teelucksingh, 2002).

PWUDs and their allies have lived in Parkdale's contested space for decades. Organizations such as the Guardian Angels, Residents Against Street Prostitution, and the Parkdale Affirmative Action Committee, all originating sometime in the late 1980s, attempted to push PWUDs and sex workers out of the community through citizen arrests, as well as scaring, shaming, and intimidating tactics (Epstein, 2018). As such, PWUDs and sex workers were identified as a significant threat to the White, heteronormative, nuclear families and communities within Parkdale. In the 1990s and early 2000s PWUDs, sex workers, and their clients were the target of numerous sting operations through the TPS and the City of Toronto, including the 
notorious Toronto Anti-Violence Intervention Strategy, colloquially known as TAVIS (Epstien, 2018). The acts of violence that ensued as a result of both TAVIS and crackdowns on sex workers contributed to some local PWUDs and sex workers disappearing (Epstien, 2018). The City of Toronto furthered this through additional structural changes, including the removal of spaces for PWUDs and sex workers to socialize, sleep, or use substances, as well as the removal of benches in certain Business Improvement Areas (Epstein, 2018).

This chapter provides findings in two broad domains. The first domain consists of findings that provide participants' perspective on a snapshot of the unsanctioned Parkdale OPS that operated between August and October 2018. The second domain provides findings on participants' perception of illegality and whether it had any impact on the operation and service provision of the unsanctioned Parkdale OPS.

\section{The Unsanctioned Parkdale OPS: A Chronology of Events}

\section{Establishing and locating the OPS}

As previously stated, the sanctioned Parkdale OPS was to open in mid-to-late summer 2018. The previous provincial government initially approved the sanctioned OPS. While there were concerns about the future of OPSs with the new provincial government, the original Parkdale site was expected to open considering its former, approved application and status. Participant 1 recounted that time:

"So yeah, I think, when [the sanctioned OPS] got rejected, when [the new government] was just like, "no," after they had like, hired everybody, and, had everything in, we had like, kind of a secret meeting and we were like okay we're doing this again like...this is fucking ridiculous like that we already had to do this with [other unsanctioned sites] in the wintertime, and I guess we gotta do it [in] Parkdale now. So, yeah, we had like an organizing meeting" (Participant 1).

When asked about how volunteers were able to gain traction in order to get the site up and running participant 2 detailed that organizers had "[meetings] with [various grassroots harm 
reduction collectives in Toronto], uh, and just like, just like group messages through Facebook, phone calls..." (Participant 2). While participant 1 mentioned that many people had volunteered under similar conditions at other unsanctioned sites, "so we already kind of knew, like, how to set up, how to tear down. We had like, like, tents and all that stuff leftover from [volunteering at other unsanctioned OPSs]" (Participant 1).

When asked about the community of PWUDs in Parkdale, Participant 1 mentioned that it is quite populous, noting that, "Parkdale has a high level of injection drug use, it's like this the second highest if you like look at the EMS maps...it's a community where lots of people use drugs are, there's lots of low-income housing..." (Participant 1). While Participant 2 added, "Um, uh, that area has a high volume of meth users...um, so, really, really high population of drug users in that area and there's, doesn't matter where you go in Toronto, there's a huge volume of drug users..." (Participant 2).

When asked about the efforts taken in order to locate the site and how the site came to open, participant 1 explained it had been a collective community effort, describing that:

"There was a survey done prior to even meeting, which was of like, peers and participants [from Parkdale] who would use the injection site, which was where they would like to see the site because you never want to put a site somewhere where people aren't already living and hanging out and buying drugs...that was actually a quite important intention for us..." (Participant 1 ).

The chosen spot, however, was not accessible for everyone, “...they picked initially on Roncesvalles which was not near enough for folks to use. They did a survey for some reason Roncesvalles was picked. Near no one came to the site..." (Participant 1). Eventually, because of the lack of individuals accessing the site, it was physically moved to the Dunn Street parkette, which was described as being "slightly busier" but, "didn't see the numbers we ever saw [at other unsanctioned OPSs] (Participant 1). Participant 2 also reflected on how the change in 
location was strategic, stating, "That's where we, we were able to do a pop-up and like, have, um, like the minimal amount of heat on us" (Participant 2). Volunteers recognized the importance of moving the site so that it would be more accessible for PWUDs to interact with the OPS. Although the community initially chose the site, participants detailed that they did not receive any complaint about the move and that it resulted in a slightly higher turnout.

\section{Operations}

After securing a designated location for the tents, volunteers noted how their days were structured from start to finish. Participant 1 recounted:

"One of us would drive a van, we had like a van shift, and we would load everything into the van...would gather, probably, like, 30 -ish minutes before we were to like, open. Pop up the tents, um, get like, yeah, like, setup, you know, certain things went into the injection side, we would set up an injection tent, and then like, kind of have like, a half tent where you will be able to get like, distribution of supplies, so if you wanted to get a crack kit or something like that. Um, test the oxygen, we would pull two rigs of Naloxone in case somebody, maybe, was gonna overdose, you know, like, have you go to the tables and all that stuff. Um, and then, like, designate you know, like, who's the nurse, who's the peer worker, and who's gonna do outreach, and that type of stuff." (Participant 1)

Participant 2 added that before starting all volunteers would engage in, “...just like a

briefing, like, checking in on how people are feeling, uh, what they want to do, where they want to work..." (Participant 2). This statement highlights a particular strategy the site utilized to empower volunteers, allowing them to choose or change positions based on how they were feeling and their wishes. Following this, and once the tents had been put up, participant 2 described how the site operated once open:

"So someone would come in, we'd ask them, uh, what they're using...uh, we wouldn't, uh, ask names. Um, and they would ask, like, "Oh I need, uh, injection supplies," we'd ask them, "what gauge, what length of needle?" there's short tip, long tip, 27 to 30-gauge needle. So yeah, we would ask "cause people have preference...s so yeah, uh, they would come in, shoot up, uh, they could chill for like, 10,15 minutes depending on how many people we had. Um, and then we clean up their station and more people would come in and repeat. Uh, but we had 
always asked what substance they were using, um, so we knew like if an overdose happened, what we would need to do...we would ask like, if they had like, other things in their system like, uh, benzos, or if they've used today already, if they've overdosed recently." (Participant 2)

Participant 1 also mentioned the importance of having community members as volunteers, stating that they could be, "anyone from like, someone who works in an OPS as a peer worker, or someone who is familiar with Parkdale. Who knows, buys, or deals in Parkdale, injects in Parkdale, whatever" (Participant 1). Participant 1 also detailed their community outreach efforts, stating that they would have, "two outreach workers and just like, have them like, walk up and down like, the hotspots...that was successful” (Participant 1). Participant 1 also mentioned the importance of engagement with community members in the operation of the site and how this was difficult for the Parkdale site:

"Yeah, I think with Parkdale, because it was so it was so very much like a baby step off of [other unsanctioned OPSs], like [the experiences at other unsanctioned OPSs were] very rich in that, in that like, we had community guidelines, and folks who live there like, made the rules, and work there, and we basically were like "this is your [community] and what do you need?" Versus like in Parkdale, [we] didn't have enough community to even like have that come together, you know? Um, I don't, I don't, it doesn't bother me that it wasn't like [sanctioned] or anything like that, like, that's the reason why we have OPSs here now. Because we literally open this thing up. Because everyone was dying." (Participant 1)

Having supplies readily available is a crucial component of operating an OPS, whether that be having kits available for distribution or an ample amount of supplies in the tents themselves. When asked about how volunteers were able to provide supplies at their site Participant 2 mentioned that it was due in part to, "[several grassroots collectives and health agencies] helping us out a lot." Participant 1 mentioned how they and other volunteers who worked in the field also brought in supplies, "like any of us volunteering [at the unsanctioned site] just like, packed our bags [at work] and [would] bring a bunch of shit" (Participant 2). Community collaboration was a critical piece in implementing the OPS. Without government 
funding, volunteers heavily relied on their connections to harm reduction agencies, as well as outside community organizations for support such as supplies and outreach.

Nearing the end of the shift volunteers would clear out methodically by, "[packing] everything, uh, [taking] down the tent, [folding] up the tables, [putting] everything into a truck or a moving container" (Participant 2). After cleaning up, volunteers would:

"Debrief [to] make sure everyone's okay, especially if there was an overdose or if, um, someone got too high and lashed out and was hostile... always debrief. Debrief was a very important thing to make sure that everyone's okay and leaving in a good headspace and felt supported" (Participant 2).

Participant 2 also mentioned how closing time could be quite difficult for some of the participants, explaining:

"Um, when it's, uh, when it's closing time it's really hard for a lot of people. Because a lot of the people that use the site can come and chill and eat and be warm and like, if it was cold, there's space heaters and stuff. And then when we close they have to go back out on the street and are no longer safe. Like, they might still have, uh, substances and go use [but] as we close they're at risk of overdose. So, I think that was like probably the biggest impact. Like, just going from feeling of security to having no security whatsoever." (Participant 2)

The set-up and tear-down of the OPS was methodical. To overcome any barriers due to the sites perceived illegality, volunteers utilized many strengths as highlighted within this theme. First, several volunteers had previous experience in operating an unsanctioned OPS, which was vital in mobilizing and initiating the site quickly. Second, PWUDs were involved in the creation of the site, noting how to operate most effectively for the needs of the community. Lastly, relation-building with community agencies allowed for the site to continue operating based on strategic alliances and generous donations.

\section{Day-to-day functioning}

Participants mutually agreed that the abovementioned accounts were reflective of the daily interactions and operations of the site. Participants were then asked to describe, to gain a 
more holistic view of their operations, what a 'good' and 'bad' day at the site looked like for them. Participant 1 described their 'good' day as being:

"Uh, community members like interacting with us, uh, people accessing the site and being connected to resources, so you know like, being like, "I live here I'm so happy to this is here" and us being like, "Do you need medical assistance? This is a place that you can go..." Um, nobody overdosing would be cool. Um, yeah, so I don't know, good days would just be like good interaction actually making connections with people, people coming back would be a good thing too, because in this work like success, basically looks like nobody dying. So, like, I see someone on Monday, and then they come back on Thursday, and I'm like, "This is so sick you're not dead.” (Participant 1)

While participant 2 mentioned that a 'good' day for them looked quite similar, “...a high number of clients, um, like, positive energy like, no, no like, violence, no arguments, no abuse towards staff, um, and no overdoses. And uh, yeah, good day is just like when everyone leaves happy" (Participant 2).

For participant 1, a 'difficult' operating day looked like "terrible weather [and] raining," as well as "low participation, low morale" (Participant 1). Participant 1 also reflected on their time in organizing the team, stating, "I would be like, how the fuck do I get people to be stoked? 'Cause like no one's here, and we're standing in the rain, and it feels, like, terrible" (Participant 1). Participant 2 also made mention about staff safety, mentioning that difficulty could arise due to, "uh, people, uh, being either sexually harassing staff or being violent and belligerent towards staff, um, uh, like just, people refusing to follow the rules or trashing the place, and like, that stuff just happens. People get too high, get, get, fucked up. So, um, yeah” (Participant 2).

The anticipation of mitigating impending overdoses also took a heavy toll on volunteers. While participant 1 stated that they hadn't experienced an overdose while they volunteered, participant 2 recalled the personal effects and impact it had:

"Like, overdoses can be like, be really hard on your mental health and like, and especially if like, multiple overdoses happen like, it's just because like, it's a life 
or death situation so like you went from like, adrenaline... drain... to adrenaline... drain." (Participant 2)

In asking participants for a subjective account of a 'good' and 'bad' day, I am able to detail both ends of the spectrum in the daily operations of the unsanctioned Parkdale OPS. These participant perspectives enable a detailed yet nuanced perspective of what a given day may look like, which may consist of a variety of positive or challenging aspects as described above.

\section{Closing the OPS}

Both participants expressed three main reasons for closing the OPS. The first being inclement weather, the other being lack of engagement and use of the site, and lastly the funding and maintenance of the site. Participant 2 mentioned how, "there was just one day that like, it was absolutely torrential downpour, like, we just had a lot of bad luck" (Participant 2). While participant 1 detailed the environmental concerns:

"So it started getting cold, like too cold, and it's really hard to run a site where you can't see your veins, and you don't have running water, you know, we're doing stuff in like, the mud. The teardown and the put up is like quite hard on the body. I think we closed it down, mm, because two or three nights in a row the tents fully blew over. And we - it was like a safety concern, to be honest. Because we weren't seeing enough numbers to justify it. It was just getting too dangerous, and we weren't seeing numbers enough like justify it." (Participant 1)

Participants also mentioned the difficulty in having people come to use the site, citing some possible reasons why. Participant 2 reflected that this may have been due to the location, stating, "it was just like, kind of, like, on, like, it was like across a road, and just like in this, like, park, and like, it was kind of hard to find, and uh, just, it was just like an impractical spot" (Participant 2). Participant 1 furthered this by stating:

"Uh, location was wrong. The thing was like, harm reduction like, pop-ups and stuff, word of mouth is the best way to contact people with no phones, and people have to learn that you're not a narc and you're not like trying to interact with their life and like, whatever like that. So like these things take time, and [other unsanctioned sites had been] immediately successful because people were already 
using in [that area] so they just have to hop over to a tent, you know? Um, but with Parkdale, you know, we would have needed to be established for like, I would say like, a month before people would like, trust us, you know? So it was very slow at the beginning. Um, yeah, so I mean like, the location was, it was wrong. The... word of mouth, like, we didn't have enough Parkdale people to like, go around and like, say what up? And then, the fact that like, people were already quite comfortable with injecting in their houses and stuff like that so." (Participant 1)

Participant 1 also recounted on how low turnout affected community input:

"It, it could have been like, you know, "this is our baby we created", but yeah, because of the low participation and that we hadn't, we were not able to establish ourselves for long enough, we never really got that like, community input, "What do you want to see? What [do] you want changed?" we did occasionally. People would be like, "we'd like [the OPS] facing here, and not on traffic," you know, "we'd like access to socks," but uh, yeah." (Participant 1)

While both participants mentioned that being classified as an unsanctioned site did not affect their personal endeavours in volunteering, they recognized the impact it had on funding. Participant 1 recounted this anomaly by stating, "if you want to make like, social change and, kind of, like, put yourself out there, eventually, hopefully [you] eventually get funding. But like, it was fucking tough in the beginning" (Participant 1). Participant 2 added to this by affirming that, “the government just didn't want it...we had no support. Like, a lot of people didn't know about it. Parkdale is a lot smaller and a lot less people and a lot less time to like actually, like, get numbers and like build the community" (Participant 2).

Even though both participants mentioned low turnout of PWUDs using the site, participant 2 recounted the impact it had upon closure:

"Oh [the Parkdale community] really liked it. Um, I have never heard a negative reaction from community members about [the unsanctioned site]. Um, it's a safe place where they can use not get in trouble and not get arrested, not die, uh yeah, so yeah, people are extremely positive about OPSs. People [were] really bummed out when it got shut down. And like that's a big transition for people especially like to have a service, that's so important and then have it, like, gone, like taken away." (Participant 2) 
The following domain will now provide findings on participants' perception of illegality

and whether it had any impact on the operation and service provision of the unsanctioned

Parkdale OPS. Themes to be explored include problematizing neoliberal scapegoating,

governance of people through cost-effective, evidence-based practices, as well as self-

management and regulation.

Neoliberal scapegoating and the discursive (re)construction of PWUDs as 'having' a 'problem' to 'being' the 'problem'

Both participants expressed their concerns about the scapegoating and neoliberal subjectification of PWUDs and provided a rationale as to why it persists. Participant 1 stated that in their view, it is due in part to the apathy, ignorance, and willful blindness of substance use:

"Policy and the government, and like, that type of stuff, like, they're not close enough to it, to do anything. They don't understand the speed that we need this. In February [2019] there was like, 150 more overdoses city-wide and [the provincial government] is shutting down sites, like, like, they don't understand. They don't even understand harm reduction, and they don't understand that, like, we can't approach this from a health perspective, or like, a criminalization perspective. That's not what it's about. We're literally trying to keep people alive. And if they want to, you know, move forward? They can. If they don't? That's fucking fine." (Participant 1)

Participant 2, added by stating:

"I think they just don't understand because they're not there. They don't see it, they're making decisions in their office or at home in their nice buildings, like... they don't see it like, they come visit but they, they, come visit to make themselves look good, not actually seeing what's going on. Like, so... we need more help. Like, honestly, like, we're doing the best we can. Like, [the provincial government] need[s] to like, chill out. Like, like, forget about the substances and focus on the people views. I feel like right now they're just focusing on the drug and not the people using the drug. So like, understand that like, an OPS isn't just a place for people to get high. It's a place for people to be at a safe space, it's a place for people to get resources, it's a place for people to eat. And, like, we just need help, more help than we're getting." (Participant 2) 
When asked if the lack of governmental support for consumption spaces had an impact on their resistance or activism, participant 2 mentioned, “...yeah, it hurts us and it's demoralizing, um, to have us get shut down or have a project not work but we just say fuck it let's try again, let's do it somewhere else" (Participant 2). While Participant 1 recalled:

"You know, the first day we opened, I was like, "I am finally being arrested today." So there's obviously fear around running an unsanctioned site. Like [the provincial government], when [they] like, came out with this like, bullshit, uh, consumption and treatment site situation [and] was like, "tents will not be accepted," like, "we will interact, and we will interfere," and all that stuff, we had, like, some fear around that and how to support. You know, we're all adults here, we will do shit, you know, uh, like, drug use is not a problem that we're trying to like, deal with like, we're, we're - the problem here is like criminalizing people [who] use drugs and people being literally poisoned when they're just trying to be functional in the world." (Participant 1)

Neoliberal scapegoating within this specific context is an act which emerges out of structural violence. At its core, it directs a greater focus on the assumed short-comings of the individual, misplacing the responsibility to operationalize counterproductive policies in the name of economic restructuring. Neoliberal scapegoating is performance - a means to justify a reduction in social programming and the welfare state. In this instance, government actors illustrate OPSs and PWUDs as not only individually causing higher rates of overdose and drug use, but collectively contributing to higher rates of criminality which threatens the public, civilized order of the colonial state. Foucault (1979) positions this top-down exercise of power through the individual, stating that the body is only useful if it is both subjected and productive. In using this view, PWUDs are then aggressively subjected as the innate 'problem' yet are considered unproductive due to their use, making it easier for the provincial government to substantiate its neoliberal agenda. These ideologies are used to justify the punitive measures enacted to control PWUDs and their perceived substance (mis)use. 
The halt of the initial sanctioned OPS site was both a criminalized and medicalized response. The closure was a means for the provincial government to strategize and create new medicalized models of sanctioned consumption spaces (Roy, 2018). Their strategy, which was announced in late 2018, stated that Consumption and Treatment Services (CTS) would now replace both OPSs and SCSs (Ministry of Health and Long Term Care, 2018). The new model stresses "comprehensive enforcement," "compliance," and imposes, "a new focus on connecting people with treatment and rehabilitation services," all of which utilizing medicalized discourses as a means to responsibilize and enhance the productivity of the individual (Ministry of Health and Long Term Care, 2018). The halt of the site additionally constructed PWUDs resistance to these closures as an incriminating act by opening unsanctioned OPSs even though several sanctioned OPSs continued to operate during this time. This perception of illegality is indicative of neoliberal tactics that fixate on promoting distinctions, and in this case, legal vs. illegal, to legitimize inequities.

\section{Justifying the fight: cost-effective, evidence-based governance and beyond}

Neoliberal governments often employ discourses of cost-effective and evidence-based practices as a tool in the guise of cuts to essential services. As mentioned in the previous theme, in August 2018 several OPSs that were intended to open were paused in order to investigate the "effectiveness" OPS model and whether it would remain in moving forward with the new provincial government (Jeffords \& Bowden, 2018). The subsequent pause of sites allowed for governance from a distance, a technology of power, whereby PWUDs could only access OPSs in approved spaces which the government could monitor.

Evidence-based and cost-effective practices were evident in participant interviews. Participants described why OPSs are integral to community building, the evidence that highlights 
its importance, along with advocating for an expansion of services based on this evidence. Volunteers were operating in nearly the same capacity as other sanctioned OPSs across the province yet were unfunded. Participants spoke at length about the irony of the situation in being cast a cost-saving mechanism, thereby doing the government's job. Responses also suggested that powerful community actors, such as the TPS, utilized this cost-effectiveness to their advantage, referring community members to the unsanctioned OPS without outwardly advocating or supporting the community members.

While the provincial government has cited that there was "no reason" (Shum, 2019) to have a multiple OPSs close to each other suggesting it lacks cost-effectiveness, Participant 2 provided a differing perspective about where OPSs are situated, noting that:

"All the OPSs are like, downtown...like, even from where I live? If I want to go use a safe injection site, it's about 45 minutes for me to get there. Especially if you're an addict and you're sick? You're not gonna wait 45 minutes. You're gonna find a bathroom." (Participant 2)

Participant 2, furthered by stating:

"We should have one on like, every major intersection, like, every subway stop. That' $\mathrm{d}$ be amazing. Like, I don't want it to be an inconvenience for people to get to - to be well. And like, there's literally nothing out there. Like, there's nothing you can go use safely." (Participant 2)

This passage highlights a critical note about the strategic placement of OPSs in Toronto. As it stands, almost all consumption spaces are within the Downtown core, an area that reports the highest number of opioid overdose calls across the City of Toronto (Toronto Public Health, 2019). There are several neighbourhoods outside of the Downtown core that experience similar rates of overdose, which suggests that it is more cost-effective for governments to intervene once overdose rates have reached an exorbitant proportion. Participant 1 spoke about opening an unsanctioned pop-up OPS in another area of Toronto, where there was a high rate of individuals 
experiencing overdoses. They mentioned their involvement in the pop-up was because “...that's another hotspot where there's not enough stuff. And [the provincial government] came out with this thing, like, trying to shut down sites right now and I don't know. I think, like, maybe we will have to do it again. I just don't know what's happening" (Participant 1). Further indicating that the government will only justify their interference if there is enough evidence to suggest that there is a presenting concern to them.

Participants also mentioned how their interactions with TPS were shaped in a costeffective manner as well. Volunteers mentioned that TPS, "pretty much ignored [the unsanctioned OPS]" (Participant 1) and that they would "drive by and like, check it out but I never, I never saw them interrupt us" (Participant 2). The threat of being arrested, however, was still present, "Like if [TPS] came in with a search warrant and came into the site while there's people using, people [could be] caught with substance..." (Participant 2). That being said, the likelihood of volunteers being arrested at the unsanctioned site appeared unlikely, "honestly I think if they came in and arrested all of us, that would look super bad on them, not on us. Like, I, people would be in an uproar. There'd be protest. More stuff than they want to deal with.” (Participant 2). Surmountable social pressure from the public, as described by participant 2, undeniably factors into a perceived lack of police presence, as does a calculated analysis of cost per offence. It appeared that it was in no interest of the TPS to incriminate volunteers, suggesting that charges and arrest would be too costly. Participant 1 made mention of the TPSs performance, noting:

"[TPS was] actually like fully fine about it. And then, I think a couple weeks after we opened there was like, a severe poisoning of cocaine and I think they had like, ni-, like, nine overdoses from cocaine use [in] one weekend? And they were like, "Please go to OPSs," you know? So you're seeing from like, the government side, like, "Close down those OPSs," and then the police being like "Go to OPSs." So it 
was very strange to be like, the city is giving us different messages?" (Participant 1)

It is important to note, however, that the abovementioned passages by no means reflect the experiences of PWUDs who access unsanctioned sites. Participant 1 mentioned how the police attempted to bar PWUDs from accessing the site by:

"...banning folks from like, [the street the unsanctioned OPS was on] in particular, I don't know the details of it all but people couldn't go onto the street, but cops always, like, pick on, on the people who are using drugs." (Participant 1)

PWUDs have detailed experiences with police force through violence and the confiscation of drug paraphernalia, which at times has lead to arrest and fears around extortion, especially so for Black, Indigenous, and racialized PWUDs (Bardwell, Strike, Altenberg, Barnaby, \& Kerr, 2019). Hyper-surveillance of PWUDs has also been associated with particular health concerns, which may contribute to higher rates of syringe sharing leading to a higher prevalence of infectious disease transmission (Bardwell et al., 2019). Ultimately, while volunteers expressed that there were no concerns about police violence at or within site, PWUDs continued to experience barriers to accessing services as a result.

\section{"It feels like the government is just trying to kill us:" personal obligation and}

\section{collective action as responsibilization.}

Responsibilization is a process of governance that is twofold. It manifests itself through a translation of personal autonomy into an independent, responsibility-taking subject (Pyysiäinen, Halpin, \& Guilfoyle, 2017). Responsibilization is not parallel to empowerment but a form of self-governance, suggesting that individuals or groups are not innately responsible but rather can and should be (Hache, 2007). As the colonial state divests from particular responsibilities, new communities begin to emerge, forming collective social responsibilities based on personal choice (Rose, 1996 as cited in Trnka and Trundle, 2014). While volunteers were active in educating and 
supporting one another, they also discussed their concerns regarding the practices of power and governance that furthered state interest (Trnka and Trundle, 2014). As such, volunteers were engaged in governance through self-responsibility and accountability, making direct demands to the state for care and an extension of decision-making for these services for PWUDs, by PWUDs (Epstien, 1998 as cited in Trnka and Trundle, 2014).

At the same time, it is essential to note that consumption spaces, such as OPSs, have been critiqued for supporting, constructing, and responsibilizing PWUDs, noting that these concealed spaces promote a specific order of those who use substances. This order is one that is concerned with cost, surveillance, management, and social control (Fischer, Turnbull, Poland \& Haydon, 2004). While this observation provides a relevant critique, it must be placed and interrogated within a particular context. While one could argue that the unsanctioned Parkdale OPS provides a hidden, concealed space for PWUDs to engage in acts of self-responsibilization through the management of their health, it does not consider the juxtaposition of being both unsanctioned and community-led which warrants considerable reflection. Volunteers resisted all modes of governance by utilizing their resources in fundraising and creating a community-led space that encapsulated much more than just a tent to smoke, inject, or consume. As such, this theme will primarily focus on the self-reliant responsibilization of volunteers relative to state governance.

Both participants detailed their reasoning in becoming involved with the unsanctioned Parkdale OPS. For participant 1, it was a conscious decision which noted personal responsibility as a result of lack of state care:

"Yeah I mean this is my community I'm an injection heroin user. Um, it's terrible that we have an unregulated drug supply right now and people need access to safe drugs. They need to get well, and it's a poisoning crisis where people shouldn't have to die to get well or to get high or whatever, you know? So yeah that's my motivations, it's like close to my heart, like I've lost so many friends over the 
years to the overdoses that were fully preventable if we had OPSs open, you know?" (Participant 1)

When asked about their thoughts on the halt of the sanctioned Parkdale site as a means of control, participant 2 mentioned that "we're like, kind of used to it," adding:

"Like, we're used to the government not caring, and that's why we do the illegal pop-ups because we're sick of the red tape. Like we don't care about the red tape, we don't care about all the policies that you have to do. There's 10,000 dead people and counting in um, Canada, and the States it was like 40,000 people died in a year. Um, so it's a huge issue, and like, we just don't care. Like, we don't care if we get arrested. We don't care if we have to spend a couple nights in like, holding, like, because we're trying to save lives. We're gonna keep fighting. We're not going away, like, the problem isn't going away, it's only getting worse. And, like, so we're just 'gonna keep doing it." (Participant 2)

Responsibilization, however, appeared to have a dual effect. Volunteers were able to create their space the way they wanted to, with the rules and community input that they wanted, without having to abide by state sanctions and regulations. Participant 2 noted this critical distinction, adding, "We control it. We control the rules. We control the hours, we control, um, like, how we want it to work." (Participant 2). On the other hand, participant 2 also mentioned that this responsibilization comes with certain risks:

"[Whereas] sanctioned? We have tons of rules to follow and like, um, if we break those rules we can be shut down or funding can be cut or delayed, or put on hold, or whatever. We could be arrested. Anytime. Like all of us could be coming in and they shut us down and raid us and raid the people that are there. And yeah, it is a danger for people to be using the sites, um, that are unsanctioned. It's a huge con." (Participant 2)

Both participants spoke at length about how demanding taking on this responsibility is.

Participant 2 honed in on the impact of overdoses as a particular difficulty, stating that the most challenging part of supporting PWUDs is:

"Um, the emotional toll of overdoses. Yeah, like, uh, being afraid that someone's gonna die or you're gonna fail at saving their life. Um, uh, it's a huge weight. A huge weight to carry. Like working in [OPSs] like, you're working in a life or death situation." (Participant 2) 
Participant 1 spoke about their experiences with exhaustion:

"Running an unsanctioned site is fucking hard and we already deal with so much burnout because we're, we're all working on the front lines here and, uh, like, working double days you know? Like I work, I work, fucking, I don't know, seven to 10 hours a day? And then I go to Parkdale after that and like, [work], you know, like, 14 hours in the day because it's important to me, but like we chance we are running on such a, a, amount, such a small amount and, like literally fighting for crumbs. And it feels like the government is just trying to like, kill us and like make us so tired that we stop doing it. Like some people have been working in this for like 20 years, and they fucking have like, severe trauma and like, so many of our friends have died. And so many of us have reversed overdoses it was just like every like, you know, it's just like a regular goddamn thing, and that's like, fucked up. So, um, yeah it's hard to do and it's like physically, uh, hard on the body to like, tear down and, and, you know like that, but like emotionally it's very difficult that we have to keep doing this when like it's proven that these sites fucking work, you know?" (Participant 1)

Participant 1 also reflected on PWUDs resistance to responsibilization concerning the rate of participants who accessed the site, noting:

"The reason why [the unsanctioned] Parkdale [OPS] [had low engagement] is because Parkdale has low incoming housing where folks like to use drugs. So, what we call, 'shooting galleries' or 'trap houses' where there's just like, someone's apartment and lots of people go to inject, and, that's that. So they didn't, people didn't necessarily need an OPS if they had that, you know? There's much less street injection drug use in Parkdale. It's rare when, if you don't know the places to look, where you see someone smoking crack on the street, like, obviously people are using drugs in that area, but it's much more behind closed doors. People just use in the bathrooms in Parkdale and that isn't ideal because you can't necessarily check on people or check their vitals or do stuff to them if they're like, you know, stuck between a toilet seat and a wall, so that's why we didn't see the numbers because people were already using indoors already, they had their own unsanctioned satellite sites in their own apartment building." (Participant 1)

The increasing prevalence of housing insecurity, poverty, and marginalization combined with drug prohibition and the toxic drug supply has catapulted some PWUDs into precarious spaces to use, validating why OPSs are vital across communities. A counter-resistance to these sites, however, remain prevalent as exemplified in the above passage. It is more appealing and 
comfortable for PWUDs who have access, to use in safer, enclosed spaces such as apartments or houses. While OPSs can supply sterile supplies, free food, informal counselling, and overdose prevention, several PWUDs will still choose to be independent in their use, rejecting the discursive formations of the 'responsible' PWUD.

This chapter has provided relevant historical and contextual history concerning the neighbourhood of Parkdale and the unsanctioned Parkdale OPS. This chapter also provided an overview of the site from opening to closing as well as daily accounts of operation. Themes included neoliberal scapegoating, cost-effective services, as well as self-management responsibilization. The following chapter will delve into a more in-depth analysis of these findings, implicating it within the chosen theoretical framework and literature review. 


\section{CHAPTER 6. DISCUSSION OF FINDINGS}

This chapter will discuss the major findings from the previous chapter in relation to the literature review and theoretical framework. This chapter will also revisit the research question and provide implications and limitations for its findings.

The findings showcase that indeed, the perceived illegality of the unsanctioned Parkdale OPS impacted both volunteers and their service provision. Volunteers spoke in great detail to their burnout with emotional labour and productive power, impacting themselves and their communities' well-being. However, volunteers clarified that they felt a duty being apart of the community in Toronto to mobilize and support collective efforts aimed at minimizing impacts of criminalization and the unsafe, unregulated drug supply. While volunteers expressed that the impact of illegality did not have a considerable impact on their service provision, they did highlight how the lack of funding and community mobilization played a role in the sites eventual closure.

Community design and input is an integral part of creating and operating unsanctioned OPSs, regardless of turnout. While volunteers stated it was challenging to gather community members they still recognized how important it was to have participants who were from the community engaging with the site and providing their input, similar to the Davidson et al., (2018) article. Volunteers agreed with the sentiment that the Davidson et al., (2018) article posed about the absence of referrals to community resources at unsanctioned sites. In contrast, volunteers did not feel as overtly concerned about police interaction and concealment of the site, unlike volunteers at the unsanctioned SIF (Davidson et al., 2018).

Both volunteers and the Kerr et al., (2004) article discussed the benefits of such activism, but at the cost of burnout and arrest. Due to the small number of community members and the 
short life span of the OPS, volunteers mentioned that the OPS was never too busy to accommodate community members, opposite of the McNeil et al., (2015) article. Comparable to the Wood et al., (2003) article, volunteers were successful in providing participants with a safe space, sterile supplies, assisted injecting practices, and safe disposal of sharps.

While Shaw et al., (2015) and Mitra et al., (2017) conducted research studies to analyze the feasibility of opening SISs in differing cities in Ontario, the two articles noted requests from the community which included that their SISs have connections to the community, with community consultations, as well as offering community ownership and control - all of which were prevalent within the unsanctioned OPS. Volunteers noted that it was challenging to build up the unsanctioned OPS within the community because it was open only for a short period before financial and weather pressures began to burden operations. Wallace et al., (2019) also spoke to this in their article, noting that time sensitivity impedes an OPSs success. Wallace et al., (2019) also noted how Canada's continued criminalization and stigmatization impacted PWUDs who used the site, comparable to volunteers who described neoliberal scapegoating.

Small et al., (2011) noticed that an SIS in Vancouver greatly benefitted from taking into account perspectives of PWUDs and the barriers they face in accessing the site, comparable to the unsanctioned Parkdale site. Although the SIS listened to the concerns of service users, they were unable to fully implement their feedback, as SISs prohibited anonymity, assisted injections, sale of substances between community members, and were unable to decrease wait-times or agree to remove policy on suspensions and bans (Small et al., 2011). On the other hand, considering that the Parkdale OPS was considered unsanctioned, they were able to address these concerns without fear of cuts or closing. 
Several reviewed articles also spoke on NIMBYism and the impact of outsider communities on consumption spaces. Davidson \& Howe (2014) detailed the pressure they experienced when attempting to move their services within an upper-middle-class neighbourhood, citing that it would be an undesirable community facet. While volunteers did not detail intense interactions with NIMBYs within the Parkdale neighbourhood, this difference may be due in part to the historical and contextual geography of the area.

Articles that provided a relevant critique of harm reduction services including Elliot (2014); Moore (2009); Solai et al., (2006); Wolfson-Stofko et al., (2016); and Bunton (2001), evaluated consumption spaces that were approved and funded by the state in a neoliberal lens. This vital distinction may account for the differences in the surveillance and responsibilization of PWUDs between this study and the articles as mentioned above. There are significant, characteristic differences between the unsanctioned Parkdale OPS and the sanctioned consumption spaces within these articles which cite concern with systemic barriers, prohibition of certain populations (i.e., young people or people who are pregnant), as well as audit culture and tax-payer efficiencies (Fischer et al., 2004; Solai et al., 2006; Wolfson-Stofko et al., 2016).

Governmentality is a theoretical framework that is concerned with public order, the responsible citizen, and self-governance. Similar to the literature review analysis, governmentality supports and opposes the findings of this study. Findings within this research suggest that the unsanctioned OPS had innate differences in comparison to the sanctioned OPS model, specifically in terms of surveillance and control of PWUDs. It is undeniable that the unsanctioned Parkdale OPS did provide a concealed space for PWUDs to engage in civil disobedience, thereby pushing PWUDs out of sight in the orderly, public space. However, as participants described, this is contextual to the neighbourhood as public use is infrequent due to 
the prevalence of housing insecurity. Volunteers perceived that this might be one of the few reasons why the site received low rates of participants.

This study cannot determine alone why PWUDs seek out OPSs. OPSs provide not only sterile equipment and a safe environment for individuals to use, but also a community space to gather, eat, and converse. PWUDs can face extreme physical and or symbolic violence from outsider communities. With OPSs being community-led and driven, these safe spaces provide PWUDs with a place to engage with community and receive non-judgemental and nonstigmatizing support. These spaces also provide knowledge translation as well as the potential to increase self-esteem and confidence. Compared to other spaces where PWUDs may be unsafe to engage with, OPSs are spaces where community members are welcomed and accepted. Governmentality would suggest that accessing OPSs is an act of governance by way of personal accountability to one's health. This suggestion, however, leaves no room for a nuanced discussion on the relation between pleasure and substance use or social interaction and community building.

The unsanctioned OPS was not a means to inform PWUDs on how to avoid criminal behaviour like Iacobucci \& Freih (2018) suggests but rather, participating in the site could be considered 'criminal behaviour' by government actors considering its perceived illegality. Conversely, governmentality does provide relevant conceptualizations on the impact of governance of both volunteers and PWUDs. The opening of the unsanctioned site was an act of activism and disobedience to further the implementation of sanctioned OPSs, which result in OPSs that govern and reproduce social norms of productivity and responsibility. Regardless of sanction, governments continue to construct volunteers and PWUDs as chaotic subjects who contribute to public disorder and deviance. 


\section{Limitations and Strengths}

There are several limitations of this study. First, this study had an incredibly small sample size with only two participants. Having more participants, and centring the voices of service users, would have been advantageous to the study as it would provide a richer perspective of the impact of perceived illegality. Secondly, with the site being inactive, this study was unable to capture a holistic picture of the inner workings of the site. The organizations through which participants were recruited from also held similar values of radical harm reduction praxis, possibly skewing the sample of participants recruited. Further, this research is limited to the neighbourhood of Parkdale and would stimulate differing results if placed within a different area, thus making it not generalizable.

Meanwhile, there are also many strengths this study offers. The foremost strength is this study's originality. While other articles have discussed the perception of illegality with unsanctioned OPS, none have detailed the unique instance of a shift in government, causing this perception of illegality. This study heavily focused on the impact of a change in governance and the exceptionality of opening 'illegal' OPSs while 'legal' OPSs continued to operate.

\section{Implications}

In terms of implications, more research must be conducted not only on unsanctioned consumption spaces but the criminalization of substances and PWUDs. Research on these topics must continue to identify how criminalization tactics are justified more frequently with marginalized communities including Black, Indigenous, racialized, and newcomer communities while privileged communities receive medicalization which includes privileged, White, uppermiddle-class communities. This distinction maintains and reproduces stigma, criminalization, discrimination, and disenfranchisement of marginalized groups. 
Due to the fact that the OPS model is now extinct in Ontario, the implications of this research for policy would either call for a reversal of the decision or, for CTSs to systematically build off of the same principles of community needs, inclusion, and ownership. Of course, CTSs would have to adhere to specific policies and procedures that challenge these ethics; however, there are ways in which staff members can challenge these efforts to decrease overdose, violence, and discrimination. 


\section{CHAPTER 7. CONCLUSION}

Prior to beginning the research process, I began to engage within a reflexive practice in anticipating the journey I was about to embark on. I drew upon my experience within the harm reduction field, my biases and hidden assumptions as well as critical harm reduction praxis. I questioned my subjectivities, relationship and engagement with my communities, as well as how this research may impact not just me, but the participants in moving forward within the field. Considering my subjectivities and holding the position of a student researcher, I reflected upon the privileged knowledge and power I have and the strategies I can utilize to disrupt these notions while acknowledging the imbalances at hand.

The first phase was to acknowledge what constitutes truth, identifying that this research will centre the voices of those who provide their knowledge and expertise, balancing both participants' voices as reality along with my analysis. I used journaling as a tool for myself throughout writing this study to keep track of things that were coming up for me and new critical approaches to practice. Participants of the study were involved in every aspect of producing this study, including the structuring of the interview guide, transcription, editing, and writing. Participants were also engaged in conversation after their interviews about possible abstract concepts to be addressed and the perceived value of the research concerning their personal praxis.

This research captured a brief moment in time, detailing the livelihood of the unsanctioned Parkdale OPS. Its opening was an act of resistance, a symbolic space that opposed state power by recognizing the need of the community and the need of PWUDs. This study used a case study methodology to provide a holistic overview of the unsanctioned OPS from its launch to closure, situating it within historical and geographical contexts. This study also utilized 
a governmentality framework, situating the site within a framework of neoliberalism and selfgovernance — the findings of this study showcase the impact of perceived illegality for service providers and service provision. Volunteers contested this perceived illegality, but by doing so, they engaged in self-responsibilization tactics accounting for government apathy towards criminalization and the war on drugs. Volunteers commitment to PWUDs and community mobilization continued an across-province effort for an increase of pop-up OPSs. Lack of police intervention, as experienced by volunteers, is not a unanimous experience at unsanctioned OPSs, thus necessitating further systemic change beyond decriminalization. Indifference and inaction due to the unsafe drug supply, complicated by neoliberal, conservative governments will continue to contribute to the rise of preventable overdoses and deaths. The OPS model should not be the concern; rather, the governments' preoccupation with evidence-based, cost-saving mechanisms within the settler state that privileges profit over people. 


\section{LIST OF REFERENCES}

Bañares, I. (2018, August 14). Police warn of 'dangerous narcotics' after seven fatal overdoses in 12 days. Retrieved February 2, 2019, from The Toronto Star:

https://www.thestar.com/news/gta/2018/08/14/police-warn-of-dangerous-narcotics-after-sevenfatal-overdoses-in-12-days.html

Bunton, R. (2001). Knowledge, embodiment and neo-liberal drug policy. Contemporary Drug Problems , 28, 221-243.

Carter, S. M., \& Little, M. (2007). Justifying Knowledge, Justifying Method, Taking Action: Epistemologies, Methodologies, and Methods in Qualitative Research. Qualitative Health Research , 17 (10), 1316-1328.

City of Toronto. (2019, February 21). Toronto Overdose Information System. Retrieved February 24, 2019, from City of Toronto: https://www.toronto.ca/community-people/healthwellness-care/health-inspections-monitoring/toronto-overdose-information-system/

Creswell, J. (2013). Five Qualitative Approaches to Inquiry. In J. Creswell, Qualitative inquiry and research design: choosing among five traditions (pp. 69-110). Thousand Oaks, CA: Sage.

Davidson, P. J., \& Howe, M. (2014). Beyond NIMBYism: Understanding community antipathy toward needle distribution services. International Journal of Drug Policy , 25 (3), 624632.

Davidson, P. J., Lopez, A. M., \& Kral, A. H. (2018). Using drugs in un/safe spaces: Impact of perceived illegality on an underground supervised injecting facility in the United States. International Journal of Drug Policy, 53, 37-44. 
Elliot, D. (2014). Debating Safe Injecting Sites in Vancouver's Inner City: Advocacy, Conservatism, and Neoliberalism. Contemporary Drug Problems , 41 (1), 5-40.

Fischer, B., Turnbull, S., Poland, B., \& Haydon, E. (2004). Drug use, risk and urban order: examining supervised injection sites (SISs) as 'governmentality'. International Journal of Drug Policy, 15 (5-6), 357-365.

Gaetz, S. (2015). A pragmatic, humanistic and effective approach to addictions: The Importance of Harm Reduction. In Canadian Observatory on Homelessness, The Homeless Hub, \& C. O. Inclusion Working Group (Ed.), Homelessness is Only One Piece of My Puzzle: Implications for Policy and Practice. Toronto, Ontario, Canada: The Homeless Hub Press.

Gatehouse, J. (2018, March 27). Opioid overdose deaths reach record level in Canada. Retrieved February 24, 2019, from CBC The National: https://www.cbc.ca/news/thenational/national-today-newsletter-opioid-fentanyl-cricketcolombia-1.4593667

Giovannetti, J., \& Hauen, J. (2018, August 20). Activist group opens unsanctioned overdose-prevention site in Toronto, despite Ford government freeze. Retrieved February 2, 2019, from The Globe and Mail: https://www.theglobeandmail.com/canada/article-activistgroup-defies-doug-ford-by-opening-unsanctioned-overdose/

Glauser, W. (2018). New hope for unsanctioned safe injection site. Canadian Medical Association Journal , 190 (3), 90-91.

Goldman, J. (2018, July 25). Toronto's board of health calls on feds to decriminalize all drugs. Retrieved February 24, 2019, from NOW Toronto: https://nowtoronto.com/news/decriminalization-drugs/ 
Gordon, T. (2006). Neoliberalism, Racism, and the War on Drugs in Canada. Social Justice, 33 (1), 59-78.

Gray, J. (2007). (Re)considering Voice. Qualitative Social Work, 5 (2), 119-138.

Hardy, M. (2013). Practitioner perspectives on risk: Using governmentality to understand contemporary probation practice. European Journal of Criminology, 11 (3), 303-318.

Hunter, M. (2002). Rethinking epistemology, methodology, and racism: or, is White sociology really dead? Race and Society, 5 (2), 119-138.

Iacobucci, A. C., \& Frieh, E. C. (2018). (In)dependence and addictions: Governmentality across public and private treatment discourses. Theoretical Criminology, 22 (1), 83-98.

Kerr, T., Oleson, M., \& Wood, E. (2004). Harm-reduction activism: a case study of an unsanctioned user-run safe injection site. Canadian HIV/AIDS Policy \& Law Review , 9 (2), 1319.

Khenti, A. (2014). The Canadian war on drugs: Structural violence and unequal treatment of Black Canadians. International Journal of Drug Policy , 25 (2), 190-195.

Kolla, G., Strike, C., Watson, T., Jairam, J., Fischer, B., \& Bayoumi, A. M. (2017). Risk creating and risk reducing: Community perceptions of supervised consumption facilities for illicit drug use. Health, Risk \& Society, 19 (1-2), 91-111.

MacKay, R. (2018). The Beginning of Drug Prohibition in Canada: What's Past Is Prologue. Queen's Quarterly, 125 (4).

MacNeil, J., \& Pauly, B. (2010). Impact: a case study examining the closure of a large urban fixed site needle exchange in Canada. Harm Reduction Journal, 7 (11).

Mathebane, M. S., \& Sekudu, J. (2018). A contrapuntal epistemology for social work: An afrocentric perspective. International Social Work , 61 (6), 1154-1168. 
McNeil, R., Kerr, T., Lampkin, H., \& Small, W. (2015). "We need somewhere to smoke crack": An ethnographic study of an unsanctioned safer smoking room in Vancouver, Canada. International Journal of Drug Policy, 26 (7), 645-652.

McNeil, R., Small, W., Lampkin, H., Shannon, K., \& Kerr, T. (2014). "People Knew They Could Come Here to Get Help": An Ethnographic Study of Assisted Injection Practices at a Peer-Run 'Unsanctioned' Supervised Drug Consumption Room in a Canadian Setting. AIDS and Behavior, 18 (3), 473-485.

Mitra, S., Rachlis, B., Scheim, A., Bardwell, G., Rourke, S., \& Kerr, T. (2017). Acceptability and design preferences of supervised injection services among people who inject drugs in a mid-sized Canadian city. Harm Reduction Journal , 14 (46).

Moore, D. (2009). 'Workers', 'clients' and the struggle over needs: Understanding encounters between service providers and injecting drug users in an Australian city. Social Science \& Medicine , 68 (6), 1161-1168.

Pauly, B. (2008). Harm Reduction Through a Social Justice Lens. Journal of International Drug Policy, 19 (1), 4-10.

Roe, G. (2005). Harm reduction as paradigm: Is better than bad good enough? The origins of harm reduction. Critical Public Health, 15 (3), 243-250.

Roumeliotis, F. (2015). Politics of prevention: The emergence of prevention science. International Journal of Drug Policy, 26 (8), 746-754.

Shanoff, J. (n.d.). Safe Injection Site Debate Stirs Tensions Between Toronto Progressiveness And NIMBYism. Retrieved February 24, 2019, from Environics Research: https://environicsresearch.com/insights/safe-injection-site-debate-stirs-tensions-torontoprogressiveness-nimbyism/ 
Shaw, A., Lazarus, L., Pantalone, T., LeBlanc, S., Lin, D., Stanley, D., et al. (2015). Risk environments facing potential users of a supervised injection site in Ottawa, Canada. Harm Reduction Journal, 12 (49).

Small, D., Palepu, A., \& Tyndall, M. W. (2006). The establishment of North America's first state sanctioned supervised injection facility: A case study in culture change. International Journal of Drug Policy, 17 (2), 73-82.

Small, W., Shoeveller, J., Moore, D., Tyndall, M., \& Kerr, T. (2011). Injection Drug Users Access to a Supervised Injection Facility in Vancouver, Canada: The Influence of Operating Policies and Local Drug Culture. Qualitative Health Research, 21 (6), 743-756.

Smith, C. B. (2012). Harm reduction as anarchist practice: a user's guide to capitalism and addiction in North America. Critical Public Health , 22 (2), 209-221.

Smith, C. B. (2010). Socio-spatial stigmatization and the contested space of addiction treatment: Remapping strategies of opposition to the disorder of drugs. Social Science \& Medicine , 70 (6), 859-866.

Solai, S., Dubois-Arber, F., Benninghoff, F., \& Benaroyo, L. (2006). Ethical reflections emerging during the activity of a low threshold facility with supervised drug consumption room in Geneva, Switzerland. International Journal of Drug Policy, 17 (1), 17-22.

Stake, R. (1995). The art of case study research. Thousand Oaks, CA: Sage.

The Canadian Press. (2018, April 20). Doug Ford says he's 'dead against' supervised injection sites. Retrieved February 24, 2019, from CBC News: https://www.cbc.ca/news/canada/windsor/doug-ford-says-he-s-dead-against-supervisedinjection-sites-1.4628547 
Toronto Overdose Prevention Society. (2017, August 12). Toronto Overdose Prevention Society. Retrieved February 2, 2019, from Facebook:

https://www.facebook.com/pg/TorontoOPS/about/?ref=page_internal

Villadsen, K. (2008). Freedom as self-transgression: transformations in the 'governmentality' of social work. European Journal of Social Work , 11 (2), 93-104.

Wallace, B., Pagan, F., \& Pauly, B. (2019). The implementation of overdose prevention sites as a novel and nimble response during an illegal drug overdose public health emergency. International Journal of Drug Policy, 66, 64-72.

Wolfson-Stofko, B., Curtis, R., Fuentes, F., Manchess, E., Rio-Cumba, A., \& Bennett, A. S. (2016). The portapotty experiment: neoliberal approaches to the intertwined epidemics of opioid-related overdose and $\mathrm{HIV} / \mathrm{HCV}$, and why we need cultural anthropologists in the South Bronx. Dialectical Anthropology, 40 (4), 395-410.

Wood, E., Kerr, T., Spittal, P. M., Small, W., Tyndall, M. W., O'Shaughnessy, M. V., et al. (2003). An External Evaluation of a Peer-Run "Unsanctioned" Syringe Exchange Program. Journal of Urban Health, 80 (3), 455-464.

Ye, X., Sutherland, J., Henry, B., Tyndall, M., \& Kendall, P. R. (2018). At-a-glance Impact of drug overdose-related deaths on life expectancy at birth in British Columbia. Health Promotion and Chronic Disease Prevention in Canada, 38 (6), 248-251.

Yin, R. (2009). Case study research: Design and method. Thousand Oaks, CA: Sage. 


\section{APPENDIX A}

Hello,

My name is Erika Dupuis and I am a MSW student working under the supervision of Dr. Purnima George in the Faculty of Social Work at Ryerson University. The reason that I am contacting you is that I am conducting a case study that looks to explore the experiences of service providers at the unsanctioned Parkdale OPS. I am currently seeking individuals who provided services (whether that be volunteers, nurses, student volunteers peer workers, social workers, etc.) at the OPS frequently (i.e., weekly or biweekly) as participants in this study. More specifically, I am looking to explore how the perception of illegality and being unsanctioned impacts the inner workings of the site and how this translates over to service interactions.

If this is something of interest to you or volunteers in your organization, I would ask that you send out this recruitment letter on my behalf to your listserv or email distribution list. Those who are interested in learning about the study more or who are interested in participating my email address will be provided below.

Participation in this study involves meeting myself at a location that is accessible for you for approximately an hour to an hour and a half. I will conduct an in-person interview which will be securely voice-recorded with your permission. The information will be gathered and analyzed for the purpose of my Major Research Paper. I'd like to note that your participation in this study will be completely confidential and that you will be given a chance to look over your responses once they have been transcribed.

In appreciation of your time commitment, you will receive either TTC tokens or cash towards TTC fare, a light snack and drink.

This study has been reviewed by the Ryerson University Research Ethics Board. If you are interested in participating, please contact me at edupuis@ryerson.ca.

Sincerely,

Erika Dupuis, MSW Candidate

File Number: 2019-030

Ryerson

University 


\section{APPENDIX B}

REB file number (2019-030)

Ryerson

University

\section{RESEARCH PARTICIPANTS WANTED}

Did you either volunteer or access services at the unsanctioned Parkdale Overdose Prevention Site (OPS) between August 2018 and October 2018? Did you volunteer or access services frequently (multiple times per month) during this time frame?

What:

An in-person interview, up to an hour and a half sharing your experiences as either a participant or service provider at the unsanctioned Parkdale OPS.

Interviews will be audio recorded. Participants must consent to be audio recorder in order to participate.

\section{Where:}

A location and time that is most convenient and accessible for you.

A space where you feel comfortable to discuss your experiences

\section{Purpose:}

To explore how the perception of illegality and the classification of being 'unsanctioned' by the provincial government impacts the inner workings or service provision of the OPS To center the stories of both service providers and participants strength and resilience of operating an unsanctioned site

Who:

Self-identify as someone who volunteered and provided service at the unsanctioned OPS as frequently as every week or upwards of twice per month, OR, self-identify as someone who accessed the unsanctioned OPS for services as frequently as every week or upwards of twice per month.

\section{Reimbursement}

In appreciation of your time, each participant will receive reimbursement for travel via two TTC tokens or cash equivalent along with a light snack and drink. Child care costs can be accommodated upon request.

Participation in this study is completely voluntary. You may choose whether to participate in this study or not. You may stop participating at any time and you will still be given reimbursement as described above.

Please do not feel obligated to participate in this study. For more information or to participate, please email the primary investigator, Erika Dupuis, at edupuis@ ryerson.ca

This study has been approved by the Ryerson Research Ethics Board (REB file number: 2019030) and is being conducted by a graduate student as a requirement for program completion. Research supervisor can be reached at p3george@ryerson.ca 


\section{APPENDIX C}

\section{Ryerson}

University

\section{Ryerson University \\ Consent Agreement}

You are being invited to participate in a research study. Please read this consent form so that you understand what your participation will involve. Before you consent to participate, please ask any questions to be sure you understand what your participation will involve.

\section{SPACE, PLACE, AND PERCIEVED ILLEGALITY: THE UNSANCTIONED PARKDALE OVERDOSE PREVENTION SITE}

\section{INVESTIGATORS:}

This research study is being conducted by the primary investigator, Erika Dupuis. Dr. Purnima George from the Faculty of Social Work at Ryerson University is the supervisor of this study.

If you have any questions or concerns about the research, please feel free to contact myself, Erika Dupuis at edupuis@ ryerson.ca, or Dr. Purnima George at p3george@ ryerson.ca or at her Ryerson phone number, 416-979-5000 x 7146.

\section{PURPOSE OF THE STUDY:}

In August 2018 an unsanctioned Overdose Prevention Site (OPS) was opened in Parkdale in response to the delay in opening a number sanctioned OPS across the province. The purpose of this study is to explore, understand, and give insight into the operation of an unsanctioned OPS from the perspective of service providers. There will be approximately three participants recruited for this study. In order to participate for this study, you must have volunteered/worked at the Parkdale OPS on a frequent basis. The results of this project will contribute to my major research paper, in partial completion of my Master's degree.

\section{WHAT YOU WILL BE ASKED TO DO:}

If you volunteer to participate in this study, you will be asked to do the following things:

You will be asked through email to identify a space that is accessible for you to meet. This space should be one that is comfortable for you, but also private and quiet enough for us to speak. Upon identifying this space, I will ask to meet you at a date and time that works best for you. The expected duration of this meeting should be no longer than an hour and a half. You will be required to participate in an interview with me, where I will ask you questions about your experiences in working at the Parkdale OPS. Demographic data will not be collected, but I will 
ask if you are comfortable to keep in contact after the interview via email in order to update you on any research results and findings. The interview will be recorded through a secure voice recording software on my phone. The application requires for users to enter a password before gaining access to the recordings, this is to ensure the security and privacy of individuals. I will later send you a transcribed copy of the interview for you to edit. If you wish to take out anything you said you have the right to do so. The final research paper will be provided to you through email.

\section{POTENTIAL BENEFITS:}

The potential benefit of participating in this study is to contribute to a piece of academic research that is understudied. I cannot guarantee, however, that you will receive any personal benefits from participating in this study.

\section{WHAT ARE THE POTENTIAL RISKS TO YOU AS A PARTICIPANT:}

While there is a low/minimal risk for participants, there is a risk that our discussion may be uncomfortable, triggering, or re-traumatizing for you. Considering the context of working within an OPS, there may be feelings of anxiety, grief, and hopelessness to name a few. Considering that the Parkdale OPS was unsanctioned it may also bring about feelings of anger and frustration. There is also a risk of being identified either directly or inadvertently by stating or reflecting upon certain instances or times that make you identifiable.

If at any point you begin to feel uncomfortable you may choose to skip answering a question or stop participation, either temporarily or permanently.

\section{CONFIDENTIALITY:}

I will omit any identifying information and assign a pseudonym in replacement of your name.

\section{DATA STORAGE:}

The data that is collected from participants, such as this consent form, will be held in a locked cabinet. Any files created for the purpose of this research project will be stored in a locked folder on my computer.

As previously mentioned, audio will be recorded using a secured voice recorder application that requires a passcode. This audio, which will be eventually transcribed, will be stored on a locked folder on my computer. Upon transcription the raw audio file will be permanently deleted.

This information will only be accessible to myself and Dr. Purnima George. No other party, agency, or person will have access to this data.

Upon submission of the research paper (August 2019), all data will be permanently deleted and destroyed. 


\section{DISSEMINATION:}

Participants will be contacted (through the original email provided) via email upon the completion of the transcription process. A secured .PDF file containing a passcode will be sent to the participants for them to look over and provide any questions, comments, or requests for change.

Following this process and upon completion of the research paper I will provide participants (through the original email provided) another .PDF file containing a passcode to look over the discussion and findings section to which they contributed to. Participants will be asked to look over and provide any questions, comments, or requests for change.

Upon approval of the participants the research will be submitted to both Dr. Purnima George for approval, followed by a submission to the Ryerson Digital Repository where it will then be made publically available. Participants will be emailed a link to the work once published on the Ryerson Digital Repository.

\section{COSTS TO PARTICIPATION:}

Depending on the participant, there may be costs associated with participation. This may include, transit, parking, and child care. TTC tokens or funds for TTC fare and a light snack will be provided for participants as a reimbursement.

\section{VOLUNTARY PARTICIPATION AND WITHDRAWAL:}

Participation in this study is completely voluntary. You can choose whether to be in this study or not. If any question makes you uncomfortable, you can skip that question. You may stop participating at any time and you will still be given the reimbursements described above. If you choose to stop participating, you may also choose to not have your data included in the study.

Your choice of whether or not to participate will not influence your future relations with Ryerson University or the investigators, Erika Dupuis and Dr. Purnima George, involved in the research.

\section{QUESTIONS ABOUT THE STUDY:}

If you have any questions about the research now, please ask. If you have questions later about the research, you may contact myself, Erika Dupuis at edupuis@ ryerson.ca

This study has been reviewed by the Ryerson University Research Ethics Board. If you have questions regarding your rights as a participant in this study please contact:

Research Ethics Board c/o Office of the Vice President, Research and Innovation

Ryerson University

350 Victoria Street

Toronto, ON M5B 2K3 
416-979-5042

rebchair@ryerson.ca

\section{SPACE, PLACE, AND PERCIEVED ILLEGALITY: THE UNSANCTIONED PARKDALE OVERDOSE PREVENTION SITE \\ CONFIRMATION OF AGREEMENT:}

Your signature below indicates that you have read the information in this agreement and have had a chance to ask any questions you have about the study. Your signature also indicates that you agree to participate in the study and have been told that you can change your mind and withdraw your consent to participate at any time. You have been given a copy of this agreement.

You have been told that by signing this consent agreement you are not giving up any of your legal rights.

Name of Participant (please print)

Signature of Participant

Date

I agree to be audio-recorded for the purposes of this study. I understand how these recordings will be stored and destroyed.

Signature of Participant

Date 


\section{APPENDIX D \\ Interview Guide for REB File 2019-030 - Space, Place, \& Perceived Illegality: The Unsanctioned Parkdale Overdose Prevention Site}

Interview Guide for Service Providers / Volunteers:

1. Introduction of interviewer

2. Explanation of the research

a. Asking participants how they want to structure the interview, what they would like to focus on

3. Overview of recording devices being used

4. Introduction of interviewee / demographic question surrounding their role in the unsanctioned OPS (i.e., peer worker, social worker, nurse, volunteer, etc.)

5. Topic 1: History of the OPS

a. Where did you learn about the Parkdale OPS and how did you become involved with the site?

b. How did this OPS come to be? What is your knowledge of how the site was conceived?

c. In your view, why was this site needed?

d. What were some of your motivations in wanting to volunteer with this site?

e. How often did you volunteer?

f. Why did the site close? Can you describe to me in detail the reason behind its closure?

6. Topic 2: Everyday practices

a. Walk me through a typical day at the Parkdale OPS.

b. Please describe what a good day at the Parkdale OPS would look like and what a bad day at the Parkdale OPS would look like.

c. On average, how many volunteers were there at the site per day?

7. Topic 3: Barriers and factors for success

a. In your view, what was the biggest struggle in operating the Parkdale OPS site?

b. What kept volunteers going in the face of adversity?

c. The Parkdale OPS site was considered unsanctioned by the provincial government.

i. What impact did this have on the site?

ii. Did this factor in creating barriers for providing participants with supports?

d. Was the site physically large enough for the number of participants utilizing it on a daily basis?

e. What were some consistent day-to-day struggles experienced either by volunteers or participants?

8. Further questions to come about based on semi-structured interview guide

9. Follow-up

10. Thank the participant for their time, provide emails, etc. 
Interview Guide for Participants / Those who Used the Site:

1. Introduction of interviewer

2. Explanation of the research

a. Asking participants how they want to structure the interview, what they would like to focus on

3. Overview of recording devices being used

4. Topic 1: History of the OPS

a. Where did you learn about the Parkdale OPS?

b. How did this OPS come to be? What is your knowledge of how the site was conceived?

c. In your view, why was this site needed?

d. What do you know about the community in this area?

e. What were some of your motivations in wanting to use this site?

f. How often did you visit this site?

g. Do you know why it possibly closed? How did this impact you?

5. Topic 2: Everyday practices

a. Walk me through what it would be like, start to finish, in accessing this site. What would you do?

b. Please describe what a 'good day' (it is subjective) at the Parkdale OPS would look like when you accessed it and what a 'bad day' at the Parkdale OPS would look like when you accessed it.

c. On average, was it typically busy when you accessed the site? What did it look like? What was the community like?

d. How were your relationships with the service providers?

6. Topic 3: Barriers and factors for success

a. In your view, was there any struggles you faced in physically accessing the site, or any barriers in general?

b. What made you keep coming back to use the site?

c. The Parkdale OPS site was considered unsanctioned by the provincial government.

i. What impact do you think this have on the site? On you?

d. Was the site physically large enough for the number of participants utilizing it on a daily basis?

e. Were there any consistent day-to-day struggles in accessing this site?

f. What did this site mean to you?

7. Further questions to come about based on semi-structured interview guide

8. Follow-up

9. Thank the participant for their time, provide emails, etc. 